OPEN ACCESS

Edited by:

Jue Wang,

The University of Texas Health Science Center at Tyler, United States

Reviewed by:

Cheryl Wellington,

University of British Columbia,

Canada

Gordon A. Francis,

University of British Columbia,

Canada

Carlos O. Mendivil,

University of Los Andes, Colombia

${ }^{*}$ Correspondence:

Kai Chen

chenkai@med.usc.edu orcid.org/0000-0002-8647-1182

Hussein N. Yassine

hyassine@usc.edu

${ }^{t}$ These authors have contributed equally to this work and share first

authorship

Specialty section:

This article was submitted to Lipid and Fatty Acid Research, a section of the journal

Frontiers in Physiology

Received: 26 April 2021

Accepted: 29 July 2021

Published: 06 September 2021

Citation:

Van Valkenburgh J, Meuret $C$, Martinez $A E$, Kodancha V, Solomon V, Chen $K$ and Yassine HN (2021) Understanding the Exchange of Systemic HDL Particles Into the Brain and Vascular Cells Has Diagnostic and Therapeutic Implications for Neurodegenerative Diseases.

Front. Physiol. 12:700847. doi: 10.3389/fphys.2021.700847

\section{Understanding the Exchange of Systemic HDL Particles Into the Brain and Vascular Cells Has Diagnostic and Therapeutic Implications for Neurodegenerative Diseases}

\author{
Juno Van Valkenburgh ${ }^{1 \dagger}$, Cristiana Meuret $^{2 \dagger}$, Ashley E. Martinez ${ }^{2}$, Vibha Kodancha ${ }^{2}$, \\ Victoria Solomon ${ }^{2}$, Kai Chen ${ }^{1 *}$ and Hussein N. Yassine ${ }^{2 *}$ \\ 1 Department of Radiology, Keck School of Medicine, University of Southern California, Los Angeles, CA, United States, \\ ${ }^{2}$ Department of Medicine, Keck School of Medicine, University of Southern California, Los Angeles, CA, United States
}

High-density lipoproteins (HDLs) are complex, heterogenous lipoprotein particles, consisting of a large family of apolipoproteins, formed in subspecies of distinct shapes, sizes, and functions and are synthesized in both the brain and the periphery. HDL apolipoproteins are important determinants of Alzheimer's disease (AD) pathology and vascular dementia, having both central and peripheral effects on brain amyloidbeta $(A \beta)$ accumulation and vascular functions, however, the extent to which HDL particles (HLD-P) can exchange their protein and lipid components between the central nervous system (CNS) and the systemic circulation remains unclear. In this review, we delineate how HDL's structure and composition enable exchange between the brain, cerebrospinal fluid (CSF) compartment, and vascular cells that ultimately affect brain amyloid metabolism and atherosclerosis. Accordingly, we then elucidate how modifications of HDL-P have diagnostic and therapeutic potential for brain vascular and neurodegenerative diseases.

Keywords: HDL, Alzheimer's disease, APOE, ApoA-I, vascuar, imaging

\section{INTRODUCTION}

High-density lipoprotein (HDL) particles (HDL-P) are found in the peripheral circulation as well as in the central nervous system (CNS), where they protect against disease states through a variety of physiological functions. HDL-P gain access to both parenchymal and vascular cells based on their lipid and protein composition. This allows for various degrees of exchange between blood, lymph, cerebrospinal fluid (CSF), and interstitial brain fluid compartments that is largely determined by their apolipoprotein (apo) content. Notable dissimilarities in structure and apo content distinguish periphery HDL-P from CNS HDL-P. This is likely a consequence of limited crossover between these two compartments (Mahley, 2016), however, these mechanisms have not been fully elucidated. It is pertinent to explore this gap in the literature as the manipulation of HDL-P has become 
a research focal point in recent years for their potential use as therapeutic and imaging agents, especially in the CNS.

The blood-brain barrier (BBB) and the blood-CSF barrier (BCSFB) compartmentalize CNS lipoprotein/apolipoprotein synthesis and metabolism separately from the periphery. HDL$\mathrm{P}$ are secreted by the liver and small intestine (Timmins et al., 2005; Brunham et al., 2006), whereas CNS-derived HDL-P are generated by glial cells (Fagan et al., 1999; Vitali et al., 2014). The BBB, formed by multiple cell types, including the tightly knit endothelial cells within brain microvessels, is the greatest barrier to HDL exchange. The BCSFB, in contrast, is comprised of choroid plexus (CP) epithelial cells (McPherson et al., 2007a) that are more permeable than the $\mathrm{BBB}$. This is because the junctions formed by the CP (McPherson et al., 2007a) epithelium allow for some transport of plasma proteins into the CSF (Johanson et al., 2011). In addition to these structural distinctions, the expression of transporters at the BBB and BCSFB are not the same, and the differences between their endocytic and transcytotic pathways are not clear (Strazielle and Ghersi-Egea, 2016).

While the structural, chemical, and functional properties of plasma HDL-P have been extensively studied, the properties of CSF HDL-P remain elusive due to their low abundance and high complexity (Montine et al., 1998; Yamauchi et al., 1999; Demeester et al., 2000; Koch et al., 2001; Yassine et al., 2016). Methods using gradient gel electrophoresis (Remaley et al., 2001), ion-mobility analysis (IMA), and nuclear magnetic resonance (NMR) spectroscopy have characterized three major groups of HDL-P in plasma by particle size: small $(7-8.5 \mathrm{~nm})$, medium $(8.5-10.5 \mathrm{~nm})$, and large (10.5-15 nm) (Nichols et al., 1986; Otvos et al., 1992; Jeyarajah et al., 2006; Caulfield et al., 2008). Proteomic analysis of plasma HDL isolated by density ultracentrifugation and size exclusion chromatography has identified an extensive list of over 90 proteins associated with HDL (Gordon et al., 2010; Holzer et al., 2016). In both plasma and CSF, small HDL-P are comprised of apoA-I, apoA-II, apoA-IV, apoCI/II/III, apoD, transferrin, and other proteins, whereas apoE and apoJ are found on both smaller and larger HDL-P. Also, in both compartments, HDL-P can contain single or multiple apolipoproteins (apos) (Davidson et al., 2009) that affect their structure and function. What mainly distinguishes plasma HDL$\mathrm{P}$ from CSF HDL-P is that they are enriched with apoA-I (von Zychlinski et al., 2014), while CNS HDL-P are primarily comprised of apoE (Koch et al., 2001). ApoA-I is not synthesized in the CNS, and the CSF apoA-I concentration is only $0.3 \%$ that of plasma. Furthermore, CNS-derived apoE has not been shown to cross into the periphery (Koch et al., 2017). Nevertheless, there is evidence that apoA-I is protective against CNS disease (Kawano et al., 1995; Mangaraj et al., 2016), and CNS-derived apoE has an important role in mediating amyloid-beta $(A \beta)$ clearance (Kanekiyo et al., 2014). More broadly, enhancement of endothelial transcytosis via HDL-surface modifications has been explored as a potential drug delivery strategy to the brain (Balazs et al., 2004). Therefore, the ability to support HDL-apoA-I and/or HDL-apoE transport across the $\mathrm{BBB}$ may provide significant therapeutic breakthroughs in neurodegenerative diseases. This will require a deep understanding of how the BBB and BCSFB mediate the exchange of HDL-P and their components.
Not only do apos play an important role in HDL transport and component exchange, they are also involved in acutephase response, proteolysis, immunity, $A \beta$ clearance, and vasoprotective roles (Chait et al., 2005; Getz, 2005; Vaisar et al., 2007). Specifically, HDL-P and their components play important, protective roles against both Alzheimer's disease (AD) and vascular dementia (VD) risk through mechanisms related to atherosclerosis, cerebral amyloid angiopathy (CAA), and inflammation (Gearing et al., 1995). However, it is not clear whether these neuroprotective properties are mediated by CNSderived apos, through peripheral apos entering the CNS from the periphery, or via both (Remaley et al., 2001). Understanding the neuroprotective properties of apos and how they are exchanged between the periphery and CNS is crucial to understanding how HDL-P can be modified to facilitate brain delivery. In this review, we explore the known structural and functional properties of HDL-P that enable access to the brain and vascular cells, as well as their neuroprotective and vasoprotective properties. We also present evidence to support the exchange of small, lipid-poor HDL-P between the CSF and plasma compartments across the $\mathrm{BCSFB}$ and acknowledge that the evidence for subsequent BBB exchange is weak, and therefore requires more careful, elaborate investigations. To help bridge this gap, we present evidence that HDL-P can be modified to facilitate transport across the BBB and for imaging atherosclerosis in vessel walls.

\section{Mechanisms of Lipoprotein Exchange Between the Periphery and the CNS Transport via the BBB}

The BBB is formed by multiple cell types including endothelial cells, pericytes, smooth muscle cells that shields the brain from the periphery. The highly selective nature of the $\mathrm{BBB}$ is primarily orchestrated by receptors, which help regulate bloodCNS exchange and maintain CNS homeostasis. This results in a minimal exchange between systemic and CNS-derived HDLP; however, small HDL and/or their components are suspected to traverse the BBB (Ladu et al., 2000; Koch et al., 2001; Wang and Eckel, 2014). Figure 1 and Table 1 show the relevant ligands and receptors of interest thought to play a role in the exchange of HDL across the BBB. ApoA-I have been shown in a more folded comformational state around small and lipidpoor HDL, giving them a discoidal form in lieu of spherically larger shape typlical of lipid-rich HDL-P. These discoildal forms were able to cross the BBB in vitro (Dal Magro et al., 2019), and although Martin-Nizard et al. (1989) have observed that radiolabeled $\mathrm{HDL}_{3}$ (small $\mathrm{HDL}, \mathrm{d}=1.125-1.210 \mathrm{~g} / \mathrm{mL}$ ) can bind the luminal membrane of cultured bovine brain capillary endothelial cells with high affinity, it remains unclear which receptors were responsible for this interaction. Furthermore, whether fully intact HDL-P do cross the BBB in vivo remains a point of contention. HDL are suspected to transverse the $\mathrm{BBB}$ via transcytosis - a process by which the HDL are internalized at the luminal surface by the endothelium, then trafficked to the basal membrane (Mehta and Malik, 2006). Some of the receptors of interest that express affinity for some relevant HDLassociated apos belong to the low-density lipoprotein (LDL) 


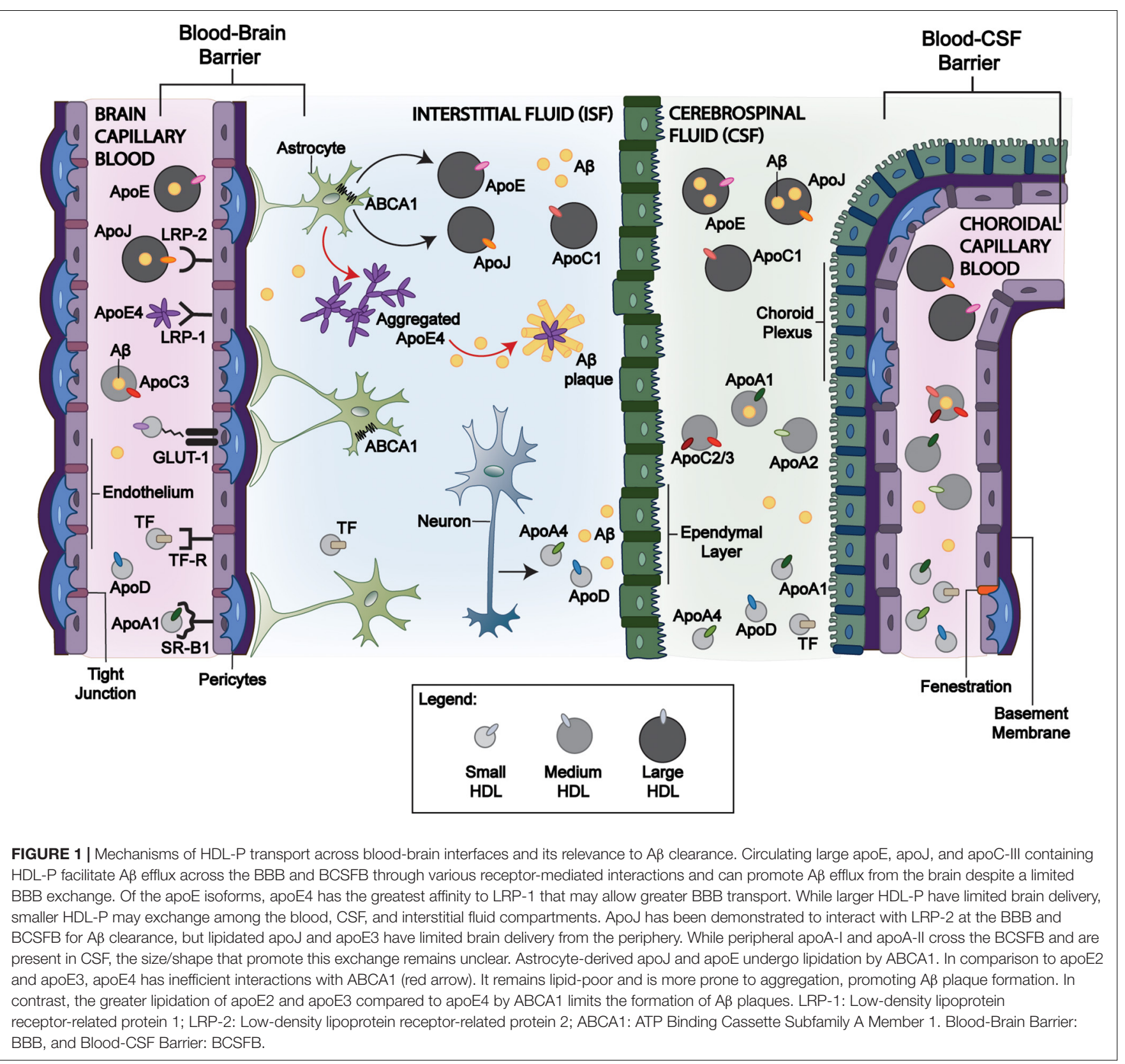

receptor superfamily. These LDL receptors, as well as scavenger receptor BI (SR-BI), are suspected to be potential mediators of HDL-transcytosis at the BBB.

The LDL receptor family includes low-density lipoprotein receptor (LDLR), very low-density lipoprotein receptor (VLDLR), LDL receptor-related protein (LRP)-1, and LRP2 (also known as megalin or gp330) (Herz and Bock, 2002). While most apos contain a receptor-binding domain, they exhibit different preferences for various LDL receptors. The binding affinity of apos to BBB-expressed receptors, such as the LDL receptor family, highlights important interactions that may facilitate the crossing of HDL through the $\mathrm{BBB}$ via receptor-mediated endocytosis and transcytosis.
LRP is expressed in brain capillary endothelium, glial cells, and neurons (Shibata et al., 2000; Herz and Bock, 2002). Its ligands of relevance for receptor-mediated endocytosis include apoE and apoJ (Bell et al., 2007; Lillis et al., 2008). LRP-1 is also expressed in smooth muscle cells (Ruzali et al., 2012), and endothelial LRP-1 transports amyloid peptides across the $\mathrm{BBB}$, contributing to its clearance from the brain (Storck et al., 2016). LDLRs are of special interest as transmembrane receptors, because they are expressed on both the luminal and abluminal sides of the $\mathrm{BBB}$ and their affinity to apoE differs by its isoforms (Dal Magro et al., 2018): apoE4 > apoE3 >> apoE2 (Johnson et al., 2014). There are, however, limitations to apoE-HDL-mediated uptake. For example, CSF-derived apoE 
TABLE 1 | Summary of HDL-associated proteins' source, function, and association.

\begin{tabular}{|c|c|c|c|c|c|c|}
\hline Protein & Source & Cross BBB? & Cross BCSFB? & Receptor interaction & Size (Meaney et al., 2001) in Plasma & CSF/Plasma Ratio \\
\hline Transferrin & $\begin{array}{l}\text { Liver, choroid } \\
\text { plexus, other } \\
\text { tissues and organs }\end{array}$ & Yes & Yes & TF-R & $\begin{array}{l}\text { Small HDL (Holzer et al., 2016; } \\
\text { Kuklenyik et al., 2018) }\end{array}$ & $\begin{array}{l}\text { 1:150 (Memisogullari and } \\
\text { Bakan, 2004; Mizuno et al., } \\
\text { 2005) }\end{array}$ \\
\hline ApoA-I & Liver, intestine & Limited BBB permeability & Yes (Stukas et al., 2014a) & $\begin{array}{l}\text { Potentially involved in SR-BI } \\
\text { mediated endocytosis of } \\
\text { HDL at BBB } \\
{[50]}\end{array}$ & $\begin{array}{l}\text { Small and large HDL } \\
\text { (Holzer et al., 2016; Kuklenyik et al., } \\
\text { 2018) }\end{array}$ & 1:700 (Koch et al., 2017) \\
\hline ApoA-II & Liver, intestine & Unknown & Yes (Montine et al., 1998) & - & $\begin{array}{l}\text { Small and large HDL (Holzer et al., } \\
\text { 2016; Kuklenyik et al., 2018) }\end{array}$ & $1: 636^{*}$ \\
\hline ApoC-I & $\begin{array}{l}\text { Liver, neurons, } \\
\text { astrocytes }\end{array}$ & $\begin{array}{l}\text { Some evidence } \\
\text { (Cudaback et al., 2012) }\end{array}$ & Yes & Inhibits LRP-1, LDLR & $\begin{array}{l}\text { Small and large HDL (Kuklenyik et al., } \\
\text { 2018) }\end{array}$ & 1:1,000 (Hu et al., 2020) \\
\hline ApoC-II & Liver & - & Yes & Inhibits LRP-1, LDLR & $\begin{array}{l}\text { Small and large HDL (Kuklenyik et al., } \\
\text { 2018) }\end{array}$ & 1:3,000 (Hu et al., 2020) \\
\hline ApoC-III & Liver & $\begin{array}{l}\text { Some evidence } \\
\text { (Zhou et al., 2019) }\end{array}$ & $\begin{array}{l}\text { Yes } \\
\text { (Koch et al., 2017) }\end{array}$ & Inhibits LDLR & $\begin{array}{l}\text { Small and large HDL } \\
\text { (Kuklenyik et al., 2018), Gordts and } \\
\text { Esko, 2018; Foley et al., 2013) }\end{array}$ & 1:2,000 (Hu et al., 2020) \\
\hline ApoD & $\begin{array}{l}\text { Astrocytes, } \\
\text { oligodendrocytes, } \\
\text { various organs }\end{array}$ & $\begin{array}{l}\text { Unknown; Hypothesized to act } \\
\text { locally rather than in circulation } \\
\text { (Provost et al., 1990) }\end{array}$ & Unknown & - & $\begin{array}{l}\text { Small and large HDL (Holzer et al., } \\
\text { 2016) }\end{array}$ & $\begin{array}{l}\text { 1:100 (Camato et al., 1989; } \\
\text { Terrisse et al., 1998) }\end{array}$ \\
\hline ApoE & $\begin{array}{l}\text { Liver, astrocytes, } \\
\text { macrophages }\end{array}$ & No (Elliott et al., 2010) & No (Elliott et al., 2010) & Binds LRP-1 & $\begin{array}{l}\text { Small and large HDL (Holzer et al., } \\
\text { 2016; Kuklenyik et al., 2018) }\end{array}$ & 1:18 (Koch et al., 2017) \\
\hline ApoJ & $\begin{array}{l}\text { Liver, astrocytes, } \\
\text { neurons }\end{array}$ & $\begin{array}{l}\text { Yes (Zlokovic et al., 1996; Bell } \\
\text { et al., 2007; Merino-Zamorano } \\
\text { et al., 2016) }\end{array}$ & Yes (Zlokovic et al., 1996) & $\begin{array}{l}\text { Transport of soluble } \\
\text { A } \beta \text {-apoJ complex and free } \\
\text { apoJ across BBB and } \\
\text { BCSFB via Megalin (LRP-2) } \\
\text { (Zlokovic et al., 1996) }\end{array}$ & $\begin{array}{l}\text { Small and large HDL (Stukas et al., } \\
2014 b)\end{array}$ & 1:950 (Koch et al., 2017) \\
\hline
\end{tabular}

*refers to unpublished data. 
is not detectable in plasma (Linton et al., 1991), and how apoE isoforms differ in brain uptake is not completely understood. Liu et al. (2012) administered adenovirus encoding human apoE3 intravenously to $\mathrm{C} 57 \mathrm{BL} / 6 \mathrm{~J}$ mice, and the detection of human apoE3 in the CSF was used as a surrogate measure of central availability. In mice receiving the administered apoE3 adenovirus, human apoE3 was expressed at high levels in the liver, leading to high levels of human apoE3 in mouse plasma. In CSF, however, human apoE3 levels were undetectable.

The findings from the above study may not be applicable to apoE4. In contrast to apoE4, human apoE3 has a lower affinity to murine LDL receptors that may limit its brain uptake at the BBB (Altenburg et al., 2008). Notably, Dal Magro et al. (2018) utilized the affinity of apoE4 for surfactant-stabilized nanoparticles (NPs), particularly polysorbate- 80 , to create an artificial protein corona that enabled the apo-decorated NP to translocate into the brain parenchyma. This process improved brain uptake three-fold compared to uncoated particles, but only at an optimal low concentration $(5 \mu \mathrm{g})$ when the NPs did not have to compete with excess lipid-free apoE4 (Dal Magro et al., 2018). While a simple process of incubation of the NP suspension with apoE4 might prove to be a successful strategy for clinical translation, further studies need to be done to characterize the stability of the artificial protein corona, especially in circulating blood, for true translational success. In addition, a possible toxic gain-offunction effect from injecting apoE4 on several brain functions may limit its use for neurodenegnerative diseases. However, these results corroborated the hypothesis of the involvement of LDL receptors, particularly LRP-1, in receptor-mediated uptake across the BBB for apoE4-coated NPs.

ApoJ is also an LRP binding ligand and is more specific to LRP-2 (Bell et al., 2007; Lillis et al., 2008). However in vivo, like apoE3, HDL-apoJ appears to have limited brain delivery. Fernández-de-Retana, et al. prepared 24 and $48 \mathrm{~nm}$ recombinant HDL (rHDL)-apoJ NPs by assembling dipalmitoylphosphatidylcholine (DMPC) with human recombinant apoJ (rapoJ) (Fernandez-de-Retana et al., 2017). These fluorescently labeled NPs were shown to accumulate in the cranial region, especially in old transgenic mice presenting a high cerebral $A \beta$ load, but parenchymal brain uptake was not demonstrated.

The other receptor of interest for the transcytosis of HDL is SR-BI, which is present within brain caveolae capillary endothelial cells and allows for the bi-directional movement of cholesteryl esters mediated by apoA-I (de Beer et al., 2001; Fung et al., 2017). Furthermore, apoA-I has demonstrated cerebral vascular protection and reduced AD risk (Zhou et al., 2019). Balazs et al. (2004) found evidence that part of cerebral apoA-I originates from plasma HDL and that brain capillary endothelial cells enriched with caveolae contain SR-BI receptors, which facilitated the selective uptake of HDL at the BBB. Furthermore, they demonstrated that SR-BI co-localizes with caveolin-1 (CAV1) on brain capillary endothelial cells. In a more recent study by Fung et al. (2017), fluorescently labeled HDL was observed via high-resolution fluorescence microscopy to be internalized by SR-BI enriched within cultured human cerebral cortex microvascular endothelial cells independent of its scaffolding protein, PDZK1. Using total internal reflection fluorescence (TIRF) microscopy, HDL was further observed to be internalized by SR-BI in a manner that was independent of proximal CAV1 and Clathrin signaling pathways. The transcytosis of HDL was, however, determined to be dependent on an unknown dynamin and cholesterol pathway. Furthermore, it was observed that HDL uptake was inhibited by the addition of $400 \mu \mathrm{g}$ of rapoA-I (Fung et al., 2017). The antagonistic effects of rapoAI on HDL transcytosis were determined to be reduced by $50 \%$ in the absence of SR-BI in the same study. Rohrer et al. (2009) found that adenosine triphosphate (ATP)-binding cassette transporter, ABCG1, located on bovine aortic enthodothelium, uptook HDL via transcytosis. This suggests that ABCG1 and SR$\mathrm{BI}$ receptors mediate the transcytosis of HDL. It is important to acknowledge that these findings were obtained from in vitro studies and there has been relatively limited information on in vivo transfer, as discussed in sections "Transport via the BCSFB" and "Apolipoprotein E."

\section{Transport via the BCSFB}

The BCSFB further guards against entry into the CNS, however, studies regarding lipoprotein exchange are limited compared to the BBB. The CP, which forms the BCSFB, secretes CSF as a medium for waste removal and nutrient uptake, thus acting as an independent circulatory system in this region of the CNS. While receptors at the $\mathrm{BCSFB}$ are not well-defined, there is evidence that LRP-2 mediates apo transport across the BCSFB (Zlokovic et al., 1996). As shown in Figure 1 and Table 1, some plasmaderived proteins are known to traverse the BCSFB. For example, while apoA-I and apoA-II mRNAs are not expressed in brain cells, they are present in the CSF and have been associated with CNS lipoproteins (Demeester et al., 2000). Stukas et al. (2014a) identified that the majority of intravenously injected lipid-free apoA-I was found in the $\mathrm{CP}$ in vivo. Like apoA-I, peripheral apoA-II is suspected to cross the BCSFB through the CP. In $\mathrm{AD}$ and control brain tissue, apoA-II immunoreactivity was observed in the cytoplasm of CP epithelium and within blood vessels consistent with a pattern for transport across the BCSFB (Montine et al., 1998). However, it is unclear if apoA-I-containing particles aid the transport of other plasma proteins into CSF or if CNS-expressed receptors/transporters directly facilitate the transcytosis of circulating proteins (Montine et al., 1998; Stukas et al., 2014a; Koch et al., 2017). What is clear is the lipidation and subsequent shape of HDL-P are in constant flux at the BCSFB.

Exchangeable apos existing on small, lipid-poor HDL-P or circulating in their lipid-free form are suspected to become lipidated in the CSF compartment following entry from the periphery. Though not as efficient as apoA-I, exchangeable apos, such as apoA-II, apoA-IV, apoC-I, apoC-II, apoC-III, and apoE, have been identified as suitable activators of ATP-binding cassette subfamily A member 1 (ABCA1) - a transport protein responable for mediating the efflux of cholesterol and phospholipids to lipid-poor/free apos (Remaley et al., 2001; Pearson et al., 2004). Fujiyoshi et al. (2007) detected ABCA1 and ABCG1 mRNAs and proteins in isolated rat $\mathrm{CP}$. Additionally, they found that both ABCA1 and ABCG1 on CP epithelium are involved in 
the transfer of cholesterol and lipids to lipid-poor apos and lipoproteins in CSF (Cavelier et al., 2006; Fujiyoshi et al., 2007). This suggests that the lipidation of delipidated and/or lipidpoor apos within the CP occurs in lieu of HDL transport across the BCSFB from the periphery. This hypothesis is supported by associations among plasma and CSF apos' concentrations (Koch et al., 2017; Hu et al., 2020). The process in which lipid-poor HDL-P or lipid-free apos (made of apoA-I, apoA-II, apoA-IV, apoCs, and apoE) originating in the periphery become lipidated by CNS-expressed transporters following transport across the BCSFB likely affects brain $A \beta$ accumulation and is discussed in section "Effect of HDL Proteins on CNS A $\beta$ Accumulation and Related Pathology."

\section{Surface Modifications to sHDL to Enhance Brain and Cellular Access}

There are several HDL modifications shown to enhance their BBB transport. Transferrin is an iron-binding protein that is well known for its antioxidant capacity and ability to traverse both the BBB and BCSFB (Table 1). In plasma, transferrin has been shown to associate with apoA-I containing HDL-P isolated by selected affinity immunosorption (Kunitake et al., 1992) and denser HDL-P isolated by ultracentrifugation (McPherson et al., 2007b). With its receptors expressed on brain capillary endothelial cells (Visser et al., 2004; Johnsen and Moos, 2016), NPs modified with transferrin (Tf) are being extensively studied for drug delivery as potential treatments for brain cancers and several neurodegenerative diseases (Wiley et al., 2013; Johnsen et al., 2019; Ullman et al., 2020). Tf receptor ligands have also been incorporated into NPs in order to further facilitate transmission across the BBB. Clark and Davis (2015) demonstrated that $80 \mathrm{~nm}$ gold NPs that were bound to Tf by an acid-cleavable linker were better able to facilitate receptor-mediated transcytosis (RMT) and avoid BBB endothelium retention by shedding surface Tf upon acidification during transcytosis. The targeted NPs showed greater permeability across BBB models in vitro and entered mouse brain parenchyma in greater amounts when compared to NPs with non-cleavable Tf. Additionally, Cui et al. (2018) constructed a dual-modified HDL containing T7, a transferrin receptor ligand, and $\mathrm{dA} 7 \mathrm{R}$, a peptide used for its glioma-homing property, that displayed higher glioma localization than that of single ligand-modified HDL. Both these findings demonstrated that incorporating Tf-like ligands into the modification of natural HDLs could prove to be a more successful methodology for the delivery of therapeutic agents across the BBB in lieu of apo-specific receptors.

dos Santos Rodrigues et al. (2019) proposed the enhanced brain targeting and gene delivery of dual-modified (PenetatrinTransferrin) liposomes encapsulating plasmid APOE2 as a new gene-targeting therapeutic approach for the treatment of AD. The liposomes were surface modified with Tf, similar to previously mentioned studies, but also incorporated the conjugation of DSPE-PEG-liposomes to Penetratin (Vaisar et al., 2007) - a cell-penetrating peptide implicated with a critical enhancement of the translocation of associated cargo, such as Pen-associated liposomes-across cellular membranes, such as the BBB. A singular intravenous injection of the dualmodified liposomes loaded with plasmid APOE2 increased apoE expression in the brain of these mice models and demonstrated successful translocation across in vitro triple co-culture BBB models. This study provides Tf-Pen modified liposomes as an effective method for brain delivery of plasmid APOE2, which has shown neuroprotective properties and a greater binding affinity to $A \beta$.

Indeed, one of the largest concerns in the clinical translation and the general success of synthetic HDLs is the low permeability and poor targeting property of HDLs across the BBB. Therefore, the study by dos Santos Rodrigues et al. (2019) highlights the efficacy of how the dual presence of the Tf ligand, in mediating transport across the BBB through RME, and the Pen peptide, in enhancing liposome internalization into cells, ultimately overcomes receptor saturation and promotes transfection in successfully transported HDL. Additionally, the surface modification also increased the stability of the liposome. The use of DSPE-PEG phospholipids minimized protein interaction and recognition by macrophage, while also reducing NP clearance through prolonged circulation. The plasmid DNA complexed to chitosan improved transfection by sterically hindering nucleases from degrading the nucleic acids and was also optimized to ensure nucleic acids released at target sites. Lastly, the low hemolytic activity of the liposomes at low phospholipid concentrations indicated blood compatibility safe for intravenous injection. This study demonstrated an effective method of apoE2 brain delivery that has potential for $\mathrm{AD}$ treatment and clinical translation.

An additional alternative method for enhanced HDL penetration across the BBB is via specific glycosylation. Zhou et al. (2020) developed a glycosylated siRNA NP delivery system (Gal-NP@siRNA) with "triple interaction" stabilization that specifically silenced BACE1 preemptively to decrease $A \beta$ levels in a transgenic $A D$ mouse model. To facilitate the transportation of the nanomedicine across the $\mathrm{BBB}$, the glycosylated nano-delivery system hacked the recycling of the glycemia-controlled glucose transporter 1 (Glut1) receptor, which resulted in the movement of Glut1 from the luminal to the abluminal side of the BBB after treatment with Gal-NP@siRNA due to glucose replenishment. The "triple interaction", more specifically, the electrostatic and hydrogen bonding interaction of the guanidinium-phosphate bridge and the fluorine-mediated hydrophobic interaction between the siRNA and the galactose-modified polymer mixture, improved the biophysiological protection of the siRNA and the stability of the NPs in blood circulation. Gal-NP@siBACE1 successfully decreased BACE1 expression for at least 3 days, consequently reducing $A \beta$ plaque levels and suppressing phosphorylated tau protein levels. This further resulted in regeneration of impaired myelin, suggesting a clearance of by-products due to biocompatibility, and contributed to the restoration of cognitive function in transgenic $\mathrm{AD}$ mice models. The long-term effects of these injections on $A \beta$ levels are not clear, however. Due to the stability, ease of formulation, and successful BBB penetration (among other factors), the Gal-NP@siBACE1 model demonstrated promising potential for clinical translation, and 
the study provides support for the use of RNA interference therapy for AD.

\section{The Effect of HDL Proteins on CNS A $\beta$ Accumulation and Related Pathology}

There is a large body of research demonstrating that various apos play a large role in attenuating toxic $\mathrm{A} \beta$ pathology in the brain. The main apos of interest are apoE, apoJ, apoA-I, and apoD. The HDL components tested for brain delivery and impact on $A \beta$ accumulation are summarized in Tables $\mathbf{1}$ and 2, and illustrated in Figure 1.

\section{Apolipoprotein E}

Apolipoprotein E (ApoE) is highly expressed in the CNS primarily by astrocytes (Elshourbagy et al., 1985; Mahley, 1988), but to a lesser extent in microglia (Butovsky et al., 2014), pericytes (Blanchard et al., 2020), and stressed neurons (Mahley and Huang, 2012). CNS-derived apoE is known to transfer phospholipids and cholesterol via interaction with ABCA1 and $A B C G 1$, and promote axonal growth via interactions with the LDLRs (Fagan et al., 1998; Wahrle et al., 2004; Kim et al., 2007). ApoE lipidation via its interaction with ABCA1 has important implications toward $A \beta$ clearance (Wahrle et al., 2004, 2005, 2008; Hirsch-Reinshagen et al., 2005; Koldamova et al., 2005; Fitz et al., 2012). Lipid-poor apoE aggregates (Hatters et al., 2006) are central to the formation of $A \beta$ plaques, and are exacerbated by the APOE4 genotype (Liao et al., 2018). The lipidation of apoE by $A B C A 1$ agonists attenuates this aggregation (Rawat et al., 2019). We have shown that preserving ABCA1 function using the ABCA1 agonist, CS-6253, enhanced the ability of astrocytes to lipidate apoE4 and degrade $\mathrm{A} \beta$ peptides. This suggests that the transport of apos into the brain, which can activate and stabilize ABCA1, offers a therapeutic approach to limit apoE aggregation and $\mathrm{A} \beta$ plaque formation as illustrated in Figure 1.

ApoE-rHDL has been presented as a novel nanomedicine for the treatment of AD. Song et al. (2014) utilized 21-27 nm apoE3-rHDL nanostructures in an attempt to lower brain $A \beta$ accumulation in an aging mouse model. The injected particles likely interact with $\mathrm{ABCA} 1$ and $\mathrm{ABCG} 1$ in vivo that modifies the shape of rHDL after injection. ApoE-rHDL injections had limited $(0.4 \% \mathrm{ID} / \mathrm{g})$ access to the CNS but demonstrated lower $\mathrm{A} \beta$ accumulation in these aging mouse models (Song et al., 2014). These effects were amplified by adding Mangostin, a model drug that accelerates $A \beta$ degradation, to apoE containing HDL-P, and demonstrated enhanced degradation of $A \beta$ and improved memory deficits (Song et al., 2016). In a more recent study, Song et al. (2018) examined the effects of rHDL's shape on its brain delivery, $\mathrm{A} \beta$ degradation, and anti- $\mathrm{AD}$ efficacy by comparing $27 \mathrm{~nm}$ spherical and discoidal apoE3NPs nanocarriers. Spherical NPs, relative to discoidal particles, exerted the best effect due to superior brain distribution after intravenous administration, powerfully reduced $A \beta$ deposition, decreased microglia activation, attenuated neurological damage, and rescued memory deficits in the same aging model. Notably, the NP size $(27 \mathrm{~nm})$ is larger than that of HDL$\mathrm{P}(7-15 \mathrm{~nm})$. It is not clear why these larger spherical particles had greater brain penetration, considering in previous studies brain delivery of apoE3-rHDL was largely unsuccessful in mouse models.

\section{Apolipoprotein $\mathbf{J}$}

Apolipoprotein $J$ (ApoJ), also known as clusterin, is an $A \beta$ chaperone, as previously noted. It is typically associated with HDL in plasma and is a major component of CSF, wherein it is found on very dense, lipid-poor HDL-like and large HDLP secreted by neurons and astrocytes (de Silva et al., 1990a,b; Suzuki et al., 2002). Cole et al. demonstrated that plasma-isolated apoJ lipidated with DMPC, as well as plasma-derived HDL, mediated $\mathrm{A} \beta$ degradation in rat microglia in vitro (Cole et al., 1999). These injections reduced $A \beta$ accumulation in a similar manner to the rHDL-apoE3, possibly by facilitating $A \beta$ efflux from the brain at the BBB. Whereas apoE, particularly apoE4, has a preference for binding LRP-1, ApoJ primarily interacts with the megalin/LRP-2 (Figure 1), where it facilitates $A \beta$ clearance across the BBB and BCSFB (Zlokovic et al., 1996; Bell et al., 2007; Verghese et al., 2013). Indeed, Zlokovic et al. (1996) found that apoJ demonstrated a higher permeability-surface area product (Pearson et al., 2004) than apoE, and Bell et al. (2007) found A $\beta 42$ complexed with apoJ was cleared $83 \%$ faster in murine models than $\mathrm{A} \beta 42$ alone.

\section{Apolipoprotein A-I}

Clinical studies have shown that lower plasma HDL cholesterol (HDL-C) and apoA-I concentrations are associated with increased severity of $\mathrm{AD}$ (Merched et al., 2000; Zuin et al., 2021). An amyloid PET brain imaging study demonstrated an association between low levels of serum HDL-C and greater cerebral amyloidosis (Reed et al., 2014). Similarly, greater serum HDL-C has been shown to be associated with greater cognitive function (Bates et al., 2017). These associations suggest a protective role for apoA-I on cognition and brain amyloidosis. While there is some evidence that plasma-derived/liver apoAI expression may not alter parenchymal $\mathrm{A} \beta$ deposition, several studies reported that apoA-I attenuates cerebral $A \beta$ angiopathy, reduces neuroinflammation, and preserves cognitive function. Specifically, Lewis et al. (2010) reported transgenic (TG) mice that overexpressed amyloid- $\beta$ precursor protein (APP) and presenilin 1 (PS1), but without apoA-I expression, exhibited learning and memory deficits, higher levels of cerebral $A \beta$ angiopathy, and $A \beta$-induced inflammation compared to APP/PS1/apoA-I-overexpressing mice. However, no significant differences in brain $A \beta$ depositions between these two groups were detected (Lewis et al., 2010). Lefterov et al. demonstrated that both lipidated and non-lipidated apoA-I attenuated A $\beta 42$ aggregation and toxicity in primary brain cells, and further showed that while apoA-I deficiency did not affect APP processing and soluble/insoluble brain parenchyma $A \beta$ levels, 12month-old APP/PS1 mice lacking apoA-I had higher insoluble $\mathrm{A} \beta$ levels in cerebral blood vessels and memory deficiencies (Lefterov et al., 2010). While these results were reaffirmed by a recent study by Robert et al. (2020), the underlying mechanisms remained unclear. 
TABLE 2 | HDL-proteins for brain delivery and impact on A $\beta$ accumulation.

\begin{tabular}{|c|c|c|c|c|c|c|c|}
\hline Protein & Lipid & $\begin{array}{l}\text { Cross } \\
\text { BBB? }\end{array}$ & Size (nm) & $\begin{array}{l}\text { Mechanism of } \\
\text { delivery }\end{array}$ & Model: in vitro, in vivo & $A D$ effect & References \\
\hline \multirow[t]{2}{*}{ ApoE } & DMPC & Yes & $21-27$ & RMT & microglial cells, primary astrocytes, liver cells & $\begin{array}{l}\text { High } A \beta \text { binding affinity, accelerated } A \beta \\
\text { degradation via lysosomal transport, } \\
\text { rescued memory deficit }\end{array}$ & Song et al., 2014 \\
\hline & & & & & AD animal model (SAMP8, SAMR1) & & \\
\hline \multirow[t]{2}{*}{ ApoE } & DMPC & Yes & 27 & RMT & $\begin{array}{l}\text { Mouse brain endothelial cell (bEnd.3) line, microglia } \\
\text { (BV2) cell line }\end{array}$ & $\begin{array}{l}\text { Enhanced } A \beta \text { binding affinity decreased } \\
\text { amyloid deposition, rescued memory deficit }\end{array}$ & Song et al., 2016 \\
\hline & & & & & AD mouse model (SAMP8) & & \\
\hline \multirow[t]{2}{*}{ ApoE } & DMPC & Yes & $26-27$ & $\begin{array}{l}\text { LDLR-mediated } \\
\text { transcytosis }\end{array}$ & $\begin{array}{l}\text { Mouse brain endothelial cell (bEnd.3) line, microglia } \\
\text { (BV2) cell line }\end{array}$ & $\begin{array}{l}\text { Enhanced } A \beta \text { binding affinity, reduced } A \beta \\
\text { deposition, attenuated neurological } \\
\text { damage, rescued memory deficits }\end{array}$ & Song et al., 2018 \\
\hline & & & & & AD animal model (SAMP8, SAMR1) & & \\
\hline \multirow[t]{2}{*}{ ApoE } & cetyl palmitate & Yes & 211 & $\begin{array}{l}\text { LDLR (LRP-1) } \\
\text { mediated uptake }\end{array}$ & $\begin{array}{l}\text { human cerebral microvascular endothelial } \\
\text { (hCMEC/D3) cells }\end{array}$ & none (not primarily discussed) & Dal Magro et al., 2018 \\
\hline & & & & & Male BALB/c mice & & \\
\hline \multirow[t]{2}{*}{ rApoJ } & DMPC & Yes & 24,48 & not discussed & Mouse J774A.1 macrophage-like cells & $\begin{array}{l}\text { Improved in vitro cholesterol efflux abilities, } \\
\text { prevented } A \beta \text { fibrillization }\end{array}$ & $\begin{array}{l}\text { Fernandez-de-Retana } \\
\text { et al., } 2017\end{array}$ \\
\hline & & & & & $\begin{array}{l}\text { Transgenic mouse model with high cerebral A } \beta \text { load } \\
\text { (APP23) }\end{array}$ & & \\
\hline \multirow[t]{2}{*}{ ApoA-I } & none & Yes & $\mathrm{N} / \mathrm{A}$ & $\begin{array}{l}\text { specific cellular } \\
\text { mediated } \\
\text { transcytosis }\end{array}$ & $\begin{array}{l}\text { Human choroid plexus epithelial cells brain } \\
\text { microvascular endothelial cells }\end{array}$ & None (not primarily discussed) & Stukas et al., 2014a \\
\hline & & & & & C57BI/6 mouse model & & \\
\hline \multirow[t]{2}{*}{ ApoA-I } & none & Yes & $\mathrm{N} / \mathrm{A}$ & $\begin{array}{l}\text { clathrin } \\
\text { independent } \\
\text { cholesterol- } \\
\text { mediated } \\
\text { endocytosis }\end{array}$ & hCMEC/D3 endothelial cell monolayers & None (not primarily discussed) & Zhou et al., 2019 \\
\hline & & & & & Wild-type male rat models & & \\
\hline \multirow[t]{2}{*}{ 4F ApoA-I } & none & Yes & $\mathrm{N} / \mathrm{A}$ & RMT & BBB endothelial cell monolayers (hCMEC/D3) & Reductions in brain $A \beta$ burden & Swaminathan et al., 2020 \\
\hline & & & & & B6SJLF1/J wild type AD mice models & & \\
\hline
\end{tabular}

RMT, receptor-mediated transcytosis; $R M E$, receptor-mediated endocytosis; $L D L R$, low-density lipoprotein receptor. 
Though Contu et al. (2019) attempted to elucidate these mechanisms in apoA-I deficient AD mice models, their study obtained contrary results using the TG2576 model. This model also uses an APP mutant which expresses high A $\beta$ levels so that by 11-13 months, these mice exhibit pathological vascular amyloid and parenchymal $\mathrm{A} \beta$ plaques. Furthermore, APP/PS1 mice have a different age of A $\beta$-pathology onset (6-9 months) than the TG2576 mice (9-12 months). Contu et al. (2019) had reported that following direct injection of $A \beta$ into the hippocampal region, apoA-I deficient mice had higher perivascular $A \beta$ drainage and less parenchymal and vascular $A \beta$ pathology than the controls. They further observed that levels of apo-associated transporters, like ABCA1, LRP-2, and LRP-1, had not increased, nor had apoD and apoE levels. Clusterin/apoJ plasma and cortex levels were, however, higher in apoA-I deficient mice. These studies highlight not only the nuances in using different $\mathrm{AD}$ mouse models to study apo-related effects on A $\beta$ pathology, but also how dyslipidemia affects certain apos' neuroprotective effects.

\section{Apolipoprotein D}

In contrast to other apos that are synthesized primarily in the liver and intestine, apolipoprotein D (ApoD) synthesis extends to the CNS and other peripheral organs such as the adrenal glands, kidneys, and pancreas (Drayna et al., 1986). ApoD is associated with lipoprotein subclasses in human CSF (Borghini et al., 1995; Koch et al., 2001). As a member of the lipocalin family, apoD shares little structural homology with other apos. As a result, apoD is unable to support the synthesis of nascent HDL (Flower et al., 2000; Rassart et al., 2000; Eichinger et al., 2007). However, the hydrophobic surface properties of apoD can explain its association with HDL-P and its ability to interact with lipid membranes (Eichinger et al., 2007). Known for its potent antioxidant properties, apoD is suspected to play a role in antioxidation in the brain. In an apoD knockout mouse model, increased sensitivity to oxidative stress was observed along with compromised nervous system function and decreased life expectancy, whereas overexpression of apoD in this mouse model resulted in increased resistance against oxidative stress (Ganfornina et al., 2008).

Along with apoE and apoJ, apoD is expressed at high levels in the prefrontal cortex, and apoD expression increases 5-to-10-fold during normal aging (Kim et al., 2009; Elliott et al., 2010). In $\mathrm{AD}$ patients, apoD expression is increased in the hippocampus, entorhinal cortex, pyramidal cells, and CSF when compared to controls (Terrisse et al., 1998; Kalman et al., 2000; Rassart et al., 2000; Belloir et al., 2001). Regarding $\mathrm{A} \beta$ pathology, dual-immunolabeling of temporal cortex tissue in control and $\mathrm{AD}$ individuals revealed that $63 \%$ of $\mathrm{A} \beta$ plaques co-localized with apoD, and increased immunoreactivity was observed in glial cells and cerebral vasculature (Desai et al., 2005). While the role of apoD in $\mathrm{AD}$ pathogenesis is unclear, it is possible that apoD partakes in $A \beta$-related pathology and/or the oxidative stress response in neurodegeneration.

\section{Apo-Peptides}

More recently, Swaminathan et al. (2020) looked at a therapeutic alternative to apoA-I-HDL-P due to their low permeability across the $\mathrm{BBB}$ in the form of $4 \mathrm{~F}$, an 18 amino acid apoA-I mimetic peptide, by examining the permeability-surface area product at the $\mathrm{BBB}$ and its effects on ${ }^{125} \mathrm{I}-\mathrm{A} \beta$ trafficking from brain-toblood and blood-to-brain. They demonstrated a $\sim 1,000$-fold higher permeability for ${ }^{125} \mathrm{I}-4 \mathrm{~F}$ compared to those determined for ${ }^{125} \mathrm{I}$-apoA-I. Treatment with $4 \mathrm{~F}$ also increased the abluminalto-luminal flux and decreased the luminal-to-abluminal flux of ${ }^{125} \mathrm{I}-\mathrm{A} \beta 42$ across BBB endothelial cell monolayers in vitro, as well as decreased the endothelial accumulation of fluorescein-labeled $A \beta 42$. These results provided a mechanistic interpretation for the reductions in brain $\mathrm{A} \beta$ burden reported in $\mathrm{AD}$ mice after oral $4 \mathrm{~F}$ administration, which represents a novel strategy for treating AD and CAA (Swaminathan et al., 2020). Our studies indicate that the ABCA1 agonist CS-6253 (modeled after the C-terminus of apoE) reduces brain apoE aggregation (Rawat et al., 2019), and attenuates AD pathology (Boehm-Cagan et al., 2016), although the brain delivery of CS-6253 is not clear. It is plausible that ABCA1 agonist peptides activate the peripheral sink of $A \beta$ by promoting the formation of $\mathrm{A} \beta$-binding lipoprotein particles into circulation.

\section{Alternative Mechanisms for How Apo-HDLs Affect CNS A $\beta$ Accumulation}

Concordantly, increased apo-HDL penetration may not solely explain its neuroprotective benefits. The Peripheral-Sink Hypothesis proposes that $\mathrm{A} \beta$-binding ligands in the periphery can promote CNS $A \beta$ efflux by sequestering $A \beta$ into the peripheral circulatory system. Indeed, increasing peripheral $A \beta$ antibodies has been shown to increase $A \beta$ efflux (Lemere et al., 2003; Deane et al., 2009) through LRP-1 (Kang et al., 2000; Shibata et al., 2000).

$\mathrm{A} \beta$ sequestration into the periphery may begin with apoJ as a chaperone from the ISF, as shown in Figure 1. Bell et al. (2007) demonstrated that apoJ cleared $\left[{ }^{125} \mathrm{I}\right]$-labeled $A \beta 40$ and $A \beta 42$ across the BBB via LRP-2. They furthermore showed that $A \beta 42-$ apoJ, compared to $\mathrm{A} \beta 42$ alone, crossed the $\mathrm{BBB}$ at an increased rate of $83 \%$. It is possible that $A \beta$ then crosses into the CSF following an influx of plasma-derived apoA-I. Human apoA-I overexpression in $\mathrm{A} \beta \mathrm{PP} / \mathrm{PS} 1$ transgenic mice was demonstrated to increase plasma HDL levels and preserve cognitive function via $A \beta$ sequestration (Paula-Lima et al., 2009; Lewis et al., 2010). Robert, et al. demonstrated that apoE and apoA-I on HDL promoted $A \beta$ transport across bioengineered human cerebral blood vessels, although in one of these studies recombinant apoE was injected into the "brain side" of the engineered vessel (Robert et al., 2017, 2020). A $\beta$ preferentially binds to HDL apoA-I, but secondarily to VLDL apoE and apoC-III (Bell et al., 2012). Once in the CSF, $A \beta$ may then cross into the periphery with an increase in plasma apoE and apoC-III concentrations. Shih et al. (2014) revealed apoC-III is an $\mathrm{A} \beta$ binding protein in the periphery. Interestingly, apoE4 carriers were shown to have lower peripheral apoE and apoC-III levels (Olivieri et al., 2007). These studies are indicative of higher plasma apoA-I, apoE, and apoC-III may 
preserve cognitive function in AD models (Lewis et al., 2010; Shih et al., 2014; Wang et al., 2019), and further demonstrate that factors driving the exchange of HDL and its components between the periphery and CNS require further elucidation.

\section{sHDL to Image Vascular Atherosclerosis and Its Relevance to the Brain}

HDL-apos have additional important roles in imaging vascular atherosclerosis that is mechanistically linked to both $\mathrm{AD}$ and vascular dementia, and other CNS diseases (Chui et al., 2012). In $\mathrm{AD}$ mouse models, genetic apoA-I deficiency showed exacerbated memory deficits and increased CAA (Lefterov et al., 2010). Since atherosclerosis and vascular $A \beta$ accumulation are mechanistically linked (Gupta and Iadecola, 2015), we discuss here properties that enable HDL-P to access blood vessels that could be pursued for vascular imaging of brain atherosclerosis. The mechanisms of HDL access to the vascular component are illustrated in Figure 2.

\section{sHDL MRI Contrast Agents}

Because of the association of vascular pathology with ADlinked biomarkers (Gupta and Iadecola, 2015) and dementia, the ability to image vasculature could be valuable for monitoring the progression of neurodegenerative diseases. HDL may be modified to include a variety of materials that generate contrast for medical imaging. These materials include radioactive or paramagnetic elements, fluorophores, and nanocrystals. One application for using HDL as an imaging agent was directed at macrophages to image atherosclerotic plaques using MRI. The first HDL contrast agent for MRI was developed by Frias et al. $(2004,2006)$. They reconstituted HDL with gadoliniumchelated lipids and a fluorescent dye with apoA-I and a cholesteryl ester core to make spherical particles, and later made similar Gd-HDL-P with discoidal morphology (Frias et al., 2004, 2006). The agent was administered to apoE KO mice, and MR imaging showed a significant increase in accumulation in abdominal aortas of the mice, which was confirmed to be due to the accumulation of the particles in macrophages and atherosclerotic plaques by ex vivo fluorescence imaging. They then improved the imaging capabilities of the particles by introducing novel gadolinium-chelating lipids, which allow for two water molecules to bind to the gadolinium instead of one, increasing the longitudinal relaxivity by a factor of four (Briley-Saebo et al., 2009). Signals can also be increased by incorporating multiple gadolinium-lipids (Gd-lipids) into each particle (Ramos-Cabrer et al., 2016). Gadolinium has also been incorporated into HDL via conjugation to apoA-I (Sriram et al., 2011; Lagerstedt et al., 2013), cholesterol (Rui et al., 2012), and to long-chain hydrophobic molecules that intercalate into the lipid coat (Carney et al., 2015). While gadolinium is the most popular element for HDL MRI contrast agents, a europium contrast agent has also been developed for use in paramagnetic chemical exchange saturation transfer (PARACEST), a highly sensitive type of MRI (Wang et al., 2015). Notably, the application of these imaging methods to either $\mathrm{AD}$ mice models or to human brains is still lacking and has great potential to help delineate the interaction of atherosclerosis with $\mathrm{AD}$ and vascular dementia pathology.

HDL MRI contrast agents have also been made with Apomimetic peptides. Synthetic peptides can confer advantages over native apoA-I in that they can be easily chemically synthesized and modified, and they do not require plasmaderived products and thus are safer for use in patients without extensive purification. Alpha-helical peptides from truncated apoA-I labeled with gadolinium have shown improved macrophage and plaque targeting in vivo compared to fulllength apoA-I (Sigalov, 2014), and increasing the Gd-loading per particle increased the atherosclerotic wall/muscle normalized enhancement ratio by $160 \%$ (Shen et al., 2015). Cormode et al. developed the Gd-HDLs, prepared particles using 18A and $37 \mathrm{pA}$, which are 18 and 37 -residue amphipathic helical peptides mimicking apoA-I function (Cormode et al., 2008a, 2009). Both types of particles had high cholesterol efflux and were selectively taken up in macrophage cells over smooth muscle cells. The signal decreased by competition with unlabeled HDL, showing that the uptake is receptor dependent. Further studies by the same group used P2A2, a peptide derived from the LDL receptor domain of apoE, for Gd- labeled HDLP (Chen et al., 2008). In macrophages, the uptake signal measured by MRI and fluorescence was higher than GdHDL made with full-length apoA-I, and the MRI signal was also higher than the signal from Gd-HDL in the aortas of apoE KO mice.

\section{HDL as a Mechanism to Reroute Contrast Agents}

HDL is directed to its natural targets by apoA-I binding. Because HDL can be reconstituted or conjugated with other peptides and proteins, it can be redirected. MRI contrast agents based on HDL have been delivered to targets other than the natural targets that are overexpressed in cardiovascular disease or cancer. HDL was conjugated with collagen-specific EP3533 peptides (EP3533-HDL) to monitor atherosclerotic plaque regression by MRI in a Reversa mouse model. Collagen, which is a marker of plaque stability, can be used as a target to distinguish between collagen and other components of the extracellular matrix. The NPs were labeled with gadolinium and administered to the atherosclerotic mice, whose regression was induced with a genetic switch. At 28 days after induction of plaque regression, there was a significant increase in MR signal from EP3533-HDL which corresponded to the increase of collagen in the plaques. Ex vivo confocal microscopy of aortic sections showed HDL colocalized with macrophages and not collagen, while EP3533-HDL colocalized with collagen and not macrophages (Chen et al., 2013).

\section{SR-BI Uptake Mechanism for Direct Cytosolic Delivery}

HDL and HDL-like NPs have been labeled with phospholipids containing fluorescent dyes such as rhodamine (Cormode et al., 2008b, 2009) and nitrobenzoxadiazole (Frias et al., 2004, 2006), 


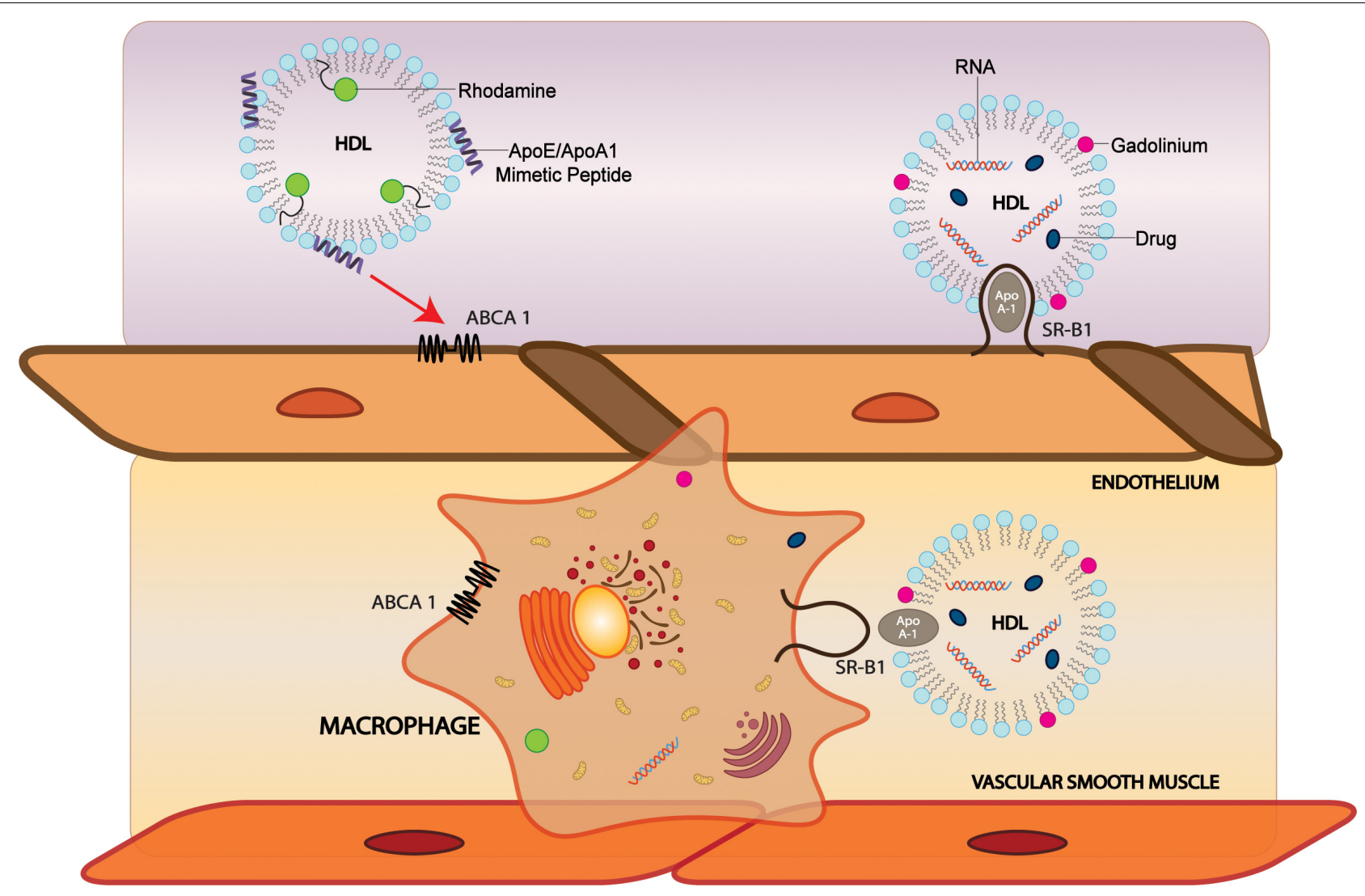

FIGURE 2 | Modification of sHDL particles can facilitate brain, vascular cell, and macrophage delivery. HDL-like NPs labeled with phospholipid-containing dyes such as rhodamine and probes conjugated with CS-6253, an ABCA1 agonist, can target ABCA1 on endothelial cells and macrophages to deliver cargo. Incorporation of MRI contrast agents such as gadolinium into HDL can increase signal. In SR-BI positive cells, sHDLs comprised of apoA-I can bind SR-BI and are taken up by the cell where cargo is delivered. ABCA1, ATP Binding Cassette Subfamily A Member 1; SR-BI, Scavenger receptor, class B type 1.

lipophilic dyes or fluorescent nanocrystals loaded into the core of the NPs (Cormode et al., 2008b; Chen et al., 2014), and with probes conjugated to the lipoprotein (Kim et al., 2014) or peptide components (Zhang et al., 2009). Because fluorescence imaging has the spatial resolution to distinguish cellular localization, it is a useful modality for elucidating the mechanism of NP interaction with cells. By labeling different NP components (core, lipid layer, protein/peptide), the localization of the components can be imaged by fluorescence.

To investigate the mechanism of drug delivery of HDL NPs, Zhang et al. (2009) developed multi-labeled nanocarriers comprised of a DiR-BOA core and an apoA-I mimetic peptide with a phospholipid coat, with fluorescein labeling on either the peptide or phospholipids. In SR-BI-positive cells, the cargo dye signal was observed in the cytosol and did not colocalize with LysoTracker, whereas the peptide and phospholipid signals were retained on the cell surface. Since SR-BI facilitates the uptake of lipids from hydrophobic cores of lipoproteins, and lipid-soluble molecules, it is not surprising that dyes and hydrophobic drugs carried to the cell by HDL can be transported into the cytosol by SR-BI. These findings suggest that via SR-BI, HDL nanocarriers are viable direct-cytosolic delivery systems for hydrophobic drugs that are prone to lysosomal degradation.

\section{PET Imaging of Atherosclerosis With sHDL}

Coupling PET tracers to HDL allows the sensitive tracers to access vascular tissues so they can be imaged with high specificity. Pérez-Medina and coworkers developed macrophage-targeting rHDLs radiolabeled with ${ }^{89} \mathrm{Zr}$ on ApoA-I ( ${ }^{89} \mathrm{Zr}$-A1-HDL) or phospholipids ( ${ }^{89} \mathrm{Zr}$-PL-HDL) for imaging atherosclerosis in murine, rabbit, and porcine models (Pérez-Medina et al., 2016). Biodistribution studies showed uptake in atherosclerotic tissues as well as kidneys, liver, spleen, and bone marrow. PET/CT of rabbit aortas with atherosclerotic lesions showed higher uptake of ${ }^{89} \mathrm{Zr}$-PL-HDL than the control $(0.31 \pm 0.10$ vs $0.16 \pm 0.03 \mathrm{~g} / \mathrm{mL}, p<0.05)$. In pigs, atherosclerotic femoral arteries had a high accumulation of ${ }^{89} \mathrm{Zr}$-PL-HDL at $48 \mathrm{~h}$ postinjection. The ability of these particles to preferentially target macrophages and plaques makes them promising imaging agents for multiple diseases.

CER-001, a pre- $\beta$-HDL mimetic containing human recombinant apoA-I and phospholipids, has also been used 
for imaging atherosclerosis. Zheng et al. (2016) labeled the apoAI component of CER-001 with ${ }^{89} \mathrm{Zr}$ and performed serial PET/CT imaging in human patients. Patients with atherosclerotic carotid artery disease $(n=8)$ were give unlabeled CER-001 $(3 \mathrm{mg} / \mathrm{kg})$ with ${ }^{89} \mathrm{Zr}$-CER-001 (10 mg) in a $1 \mathrm{~h}$ infusion. PET/CT images showed carotid artery uptake of ${ }^{89} \mathrm{Zr}$-CER-001, expressed as target-tobackground ratio $\left(\mathrm{TBR}_{\max }\right)$, was significantly increased at $24 \mathrm{~h}$ after infusion compared to initial scans $10 \mathrm{~min}$ after infusion (1.14 vs. $0.98 ; p<0.001)$ and remained increased at $48 \mathrm{~h}(1.12$, $p=0.007)$. $\mathrm{TBR}_{\text {max }}$ in plaque was 1.18 , which is significantly higher than non-plaque areas $(1.05, p<0.001)$.

${ }^{18}$ F-Fluorodeoxyglucose $\left({ }^{18} \mathrm{~F}-\mathrm{FDG}\right)$ accumulates in inflammatory cells associated with atherosclerotic plaques, but is non-specific and thus not ideal for imaging of atherosclerosis. Yong-Sang and coworkers synthesized ${ }^{68}$ Ga-labeled HDL-P labeled on the phospholipid and compared them to ${ }^{18} \mathrm{~F}-\mathrm{FDG}$ as PET probes for imaging atherosclerotic plaques (YongSang et al., 2019). The Saku group developed a PET probe to image atherosclerosis based on a 24-amino acid apoAI mimetic peptide known as Fukuoka University apoA-I Mimetic Peptide (FAMP), which promotes macrophage reverse cholesterol transport (RCT) in a cholesterol-fed mouse model (Kawachi et al., 2013). FAMP was modified with DOTA and labeled with ${ }^{68} \mathrm{Ga}$, then injected into the myocardial infarction animal model, Watanabe heritable hyperlipidemic rabbits (WHHL-MI). Atherosclerotic plaques and aortic atherosclerotic plaques in WHHL-MI rabbits showed high uptake of ${ }^{68} \mathrm{Ga}$-DOTA-FAMP compared to wild-type rabbits (Kawachi, 2015).

\section{CONCLUSION AND FUTURE PERSPECTIVES}

HDL-apos are important determinants of $\mathrm{AD}$ pathology and $\mathrm{VD}$ having both central and peripheral effects on brain $\mathrm{A} \beta$ accumulation and vascular functions. Although the extent to which HDL-P can exchange their protein and lipid components between the CNS and the systemic circulation is still not clear, HDL-P offer untapped therapeutic potential for vascular and neurodegenerative diseases through the following mechanisms that warrant additional examination:

\section{REFERENCES}

Altenburg, M., Arbones-Mainar, J., Johnson, L., Wilder, J., and Maeda, N. (2008). Human LDL receptor enhances sequestration of ApoE4 and VLDL remnants on the surface of hepatocytes but not their internalization in mice. Arterioscler. Thromb. Vasc. Biol. 28, 1104-1110. doi: 10.1161/ATVBAHA.108.164863

Balazs, Z., Panzenboeck, U., Hammer, A., Sovic, A., Quehenberger, O., Malle, E., et al. (2004). Uptake and transport of high-density lipoprotein (HDL) and HDL-associated alpha-tocopherol by an in vitro blood-brain barrier model. J. Neurochem. 89, 939-950. doi: 10.1111/j.1471-4159.2004.02373.x

Bates, K. A., Sohrabi, H. R., Rainey-Smith, S. R., Weinborn, M., Bucks, R. S., Rodrigues, M., et al. (2017). Serum high-density lipoprotein is associated with better cognitive function in a cross-sectional study of aging women. Int. J. Neurosci. 127, 243-252. doi: 10.1080/00207454.2016.1182527
1. Small HDL-P appear to gain access into the brain compartment in vitro, but further studies are required to identify their transport in vivo and the small HDL components that render these BBB and BCSF transport properties, including apo and lipid composition, size, and shape.

2. Lipid-poor HDL-P entering the brain or CSF are lipidated in the brain via interactions with ABCA1/ABCG1. This process may allow for the exchange of brain lipids with peripheral lipoproteins and has important implications for $\mathrm{A} \beta$ production and its clearance from the brain.

3. Modifying HDL-P (e.g., the addition of Tf peptide) can enhance its brain delivery via the Tf receptors at the $\mathrm{BBB}$, but applications for modifying HDL to enhance its brain delivery in neurodegenerative diseases are still lacking.

4. Even without access into the brain, some lipoproteins in the circulation can sink $A \beta$ from the brain, a process that involves lipoprotein-A $\beta$ binding in the circulation. This point is important for developing brain lipoprotein therapeutics without the prerequisite of crossing into the brain as a drug development milestone.

5. Since atherosclerosis is involved in the pathogenesis of brain amyloidosis and VD, imaging atherosclerosis in the brain via HDL NPs can delineate mechanisms of dementia in both parenchymal and vascular amyloidopathies, and guide drug treatments that have dual effects, ameliorating both atherosclerosis and vascular amyloid deposition.

\section{AUTHOR CONTRIBUTIONS}

HY and KC designed the review. JV, CM, AM, VK, and VS wrote the manuscript. All authors reviewed the manuscript.

\section{FUNDING}

HY was supported by R21AG056518, R01AG055770, R01AG054434, and R01AG067063 from the National Institute on Aging. This work was also supported by P50AG05142 from the National Institutes of Health. Funders had no role in study design, data collection, data analysis, interpretation, or writing of the report.

Bell, R. D., Sagare, A. P., Friedman, A. E., Bedi, G. S., Holtzman, D. M., Deane, R., et al. (2007). Transport pathways for clearance of human Alzheimer's amyloid beta-peptide and apolipoproteins $\mathrm{E}$ and $\mathrm{J}$ in the mouse central nervous system. J. Cereb. Blood Flow Metab. 27, 909-918. doi: 10.1038/sj.jcbfm.9600419

Bell, R. D., Winkler, E. A., Singh, I., Sagare, A. P., Deane, R., Wu, Z., et al. (2012). Apolipoprotein E controls cerebrovascular integrity via cyclophilin A. Nature 485, 512-516. doi: 10.1038/nature11087

Belloir, B., Kovari, E., Surini-Demiri, M., and Savioz, A. (2001). Altered apolipoprotein D expression in the brain of patients with Alzheimer disease. J. Neurosci. Res. 64, 61-69. doi: 10.1002/jnr.1054

Blanchard, J. W., Bula, M., Davila-Velderrain, J., Akay, L. A., Zhu, L., Frank, A., et al. (2020). Reconstruction of the human blood-brain barrier in vitro reveals a pathogenic mechanism of APOE4 in pericytes. Nat. Med. 26, 952-963. doi: 10.1038/s41591-020-0886-4 
Boehm-Cagan, A., Bar, R., Liraz, O., Bielicki, J. K., Johansson, J. O., and Michaelson, D. M. (2016). ABCA1 agonist reverses the ApoE4-driven cognitive and brain pathologies. J. Alzheimers Dis. 54, 1219-1233. doi: 10.3233/JAD160467

Borghini, I., Barja, F., Pometta, D., and James, R. W. (1995). Characterization of subpopulations of lipoprotein particles isolated from human cerebrospinal fluid. Biochim. Biophys. Acta 1255, 192-200. doi: 10.1016/0005-2760(94)0 0232-n

Briley-Saebo, K. C., Geninatti-Crich, S., Cormode, D. P., Barazza, A., Mulder, W. J., Chen, W., et al. (2009). High-relaxivity gadolinium-modified high-density lipoproteins as magnetic resonance imaging contrast agents. J. Phys. Chem. B. 113, 6283-6289. doi: 10.1021/jp8108286

Brunham, L., Kruit, J., Iqbal, J., Fievet, C., Timmins, J., Pape, T., et al. (2006). Intestinal ABCA1 directly contributes to HDL biogenesis in vivo. J. Clin. Invest. 116, 1052-1062.

Butovsky, O., Jedrychowski, M. P., Moore, C. S., Cialic, R., Lanser, A. J., Gabriely, G., et al. (2014). Identification of a unique TGF- $\beta$-dependent molecular and functional signature in microglia. Nat. Neurosci. 17, 131-143. doi: 10.1038/nn. 3599

Camato, R., Marcel, Y. L., Milne, R. W., Lussier-Cacan, S., and Weech, P. K. (1989). Protein polymorphism of a human plasma apolipoprotein D antigenic epitope. J. Lipid Res. 30, 865-875.

Carney, C. E., Lenov, I. L., Baker, C. J., MacRenaris, K. W., Eckermann, A. L., Sligar, S. G., et al. (2015). Nanodiscs as a modular platform for multimodal MR-optical imaging. Bioconjug Chem. 26, 899-905. doi: 10.1021/acs.bioconjchem.5b0 0107

Caulfield, M. P., Li, S., Lee, G., Blanche, P. J., Salameh, W. A., Benner, W. H., et al. (2008). Direct determination of lipoprotein particle sizes and concentrations by ion mobility analysis. Clin. Chem. 54, 1307-1316. doi: 10.1373/clinchem.2007. 100586

Cavelier, C., Lorenzi, I., Rohrer, L., and von Eckardstein, A. (2006). Lipid efflux by the ATP-binding cassette transporters ABCA1 and ABCG1. Biochim. Biophys. Acta 1761, 655-666. doi: 10.1016/j.bbalip.2006. 04.012

Chait, A., Han, C. Y., Oram, J. F., and Heinecke, J. W. (2005). Thematic review series: The immune system and atherogenesis. Lipoprotein-associated inflammatory proteins: markers or mediators of cardiovascular disease? J. Lipid Res. 46, 389-403. doi: 10.1194/jlr.R400017-JLR200

Chen, L., Yang, G., Monslow, J., Todd, L., Cormode, D. P., Tang, J., et al. (2014). Myeloid cell microsomal prostaglandin E synthase-1 fosters atherogenesis in mice. Proc. Natl. Acad. Sci. U S A. 111, 6828-6833. doi: 10.1073/pnas. 1401797111

Chen, W., Cormode, D. P., Vengrenyuk, Y., Herranz, B., Feig, J. E., Klink, A., et al. (2013). Collagen-specific peptide conjugated HDL nanoparticles as MRI contrast agent to evaluate compositional changes in atherosclerotic plaque regression. JACC Cardiovasc. Imaging 6, 373-384. doi: 10.1016/j.jcmg.2012.06. 016

Chen, W., Vucic, E., Leupold, E., Mulder, W. J., Cormode, D. P., Briley-Saebo, K. C., et al. (2008). Incorporation of an apoE-derived lipopeptide in highdensity lipoprotein MRI contrast agents for enhanced imaging of macrophages in atherosclerosis. Contrast Media Mol. Imaging 3, 233-242. doi: 10.1002/cmmi. 257

Chui, H. C., Zheng, L., Reed, B. R., Vinters, H. V., and Mack, W. J. (2012). Vascular risk factors and Alzheimer's disease: are these risk factors for plaques and tangles or for concomitant vascular pathology that increases the likelihood of dementia? An evidence-based review. Alzheimer's Res. Ther. 3:1. doi: 10.1186/ alzrt98

Clark, A. J., and Davis, M. E. (2015). Increased brain uptake of targeted nanoparticles by adding an acid-cleavable linkage between transferrin and the nanoparticle core. Proc. Natl. Acad. Sci. 112:12486. doi: 10.1073/pnas. 1517048112

Cole, G. M., Beech, W., Frautschy, S. A., Sigel, J., Glasgow, C., and Ard, M. D. (1999). Lipoprotein effects on Abeta accumulation and degradation by microglia in vitro. J. Neurosci. Res. 57, 504-520.

Contu, L., Carare, R. O., and Hawkes, C. A. (2019). Knockout of apolipoprotein A-I decreases parenchymal and vascular $\beta$-amyloid pathology in the $\operatorname{Tg} 2576$ mouse model of Alzheimer's disease. Neuropathol. Appl. Neurobiol. 45, 698-714. doi: $10.1111 /$ nan. 12556
Cormode, D. P., Briley-Saebo, K. C., Mulder, W. J., Aguinaldo, J. G., Barazza, A., Ma, Y., et al. (2008a). An ApoA-I mimetic peptide high-density-lipoproteinbased MRI contrast agent for atherosclerotic plaque composition detection. Small 4, 1437-1444. doi: 10.1002/smll.200701285

Cormode, D. P., Chandrasekar, R., Delshad, A., Briley-Saebo, K. C., Calcagno, C., Barazza, A., et al. (2009). Comparison of synthetic high density lipoprotein (HDL) contrast agents for MR imaging of atherosclerosis. Bioconjug. Chem. 20, 937-943. doi: 10.1021/bc800520d

Cormode, D. P., Skajaa, T., van Schooneveld, M. M., Koole, R., Jarzyna, P., Lobatto, M. E., et al. (2008b). Nanocrystal core high-density lipoproteins: a multimodality contrast agent platform. Nano Lett. 8, 3715-3723. doi: 10.1021/ nl801958b

Cudaback, E., Li, X., Yang, Y., Yoo, T., Montine, K. S., Craft, S., et al. (2012). Apolipoprotein C-I is an APOE genotype-dependent suppressor of glial activation. J. Neuroinflammation. 9:192. doi: 10.1186/1742-2094-9-192

Cui, L., Wang, Y., Liang, M., Chu, X., Fu, S., Gao, C., et al. (2018). Dual-modified natural high density lipoprotein particles for systemic glioma-targeting drug delivery. Drug Deliv. 25, 1865-1876. doi: 10.1080/10717544.2018.1519002

Dal Magro, R., Albertini, B., Beretta, S., Rigolio, R., Donzelli, E., Chiorazzi, A., et al. (2018). Artificial apolipoprotein corona enables nanoparticle brain targeting. Nanomedicine 14, 429-438. doi: 10.1016/j.nano.2017.11.008

Dal Magro, R., Simonelli, S., Cox, A., Formicola, B., Corti, R., Cassina, V., et al. (2019). The extent of human apolipoprotein A-I lipidation strongly affects the $\beta$-Amyloid efflux across the blood-brain barrier in vitro. Front. Neurosci. 13:419. doi: 10.3389/fnins.2019.00419

Davidson, W. S., Silva, R. A., Chantepie, S., Lagor, W. R., Chapman, M. J., and Kontush, A. (2009). Proteomic analysis of defined HDL subpopulations reveals particle-specific protein clusters: relevance to antioxidative function. Arterioscler. Thromb. Vasc. Biol. 29, 870-876. doi: 10.1161/ATVBAHA.109. 186031

de Beer, M. C., Durbin, D. M., Cai, L., Jonas, A., de Beer, F. C., and van der Westhuyzen, D. R. (2001). Apolipoprotein A-I conformation markedly influences HDL interaction with scavenger receptor BI. J. Lipid Res. 42, 309313.

de Silva, H. V., Harmony, J. A., Stuart, W. D., Gil, C. M., and Robbins, J. (1990b). Apolipoprotein J: structure and tissue distribution. Biochemistry 29, 5380-5389. doi: 10.1021/bi00474a025

de Silva, H. V., Stuart, W. D., Duvic, C. R., Wetterau, J. R., Ray, M. J., Ferguson, D. G., et al. (1990a). A $70-\mathrm{kDa}$ apolipoprotein designated ApoJ is a marker for subclasses of human plasma high density lipoproteins. J. Biol. Chem. 265, 13240-13247.

Deane, R., Bell, R. D., Sagare, A., and Zlokovic, B. V. (2009). Clearance of amyloid-beta peptide across the blood-brain barrier: implication for therapies in Alzheimer's disease. CNS Neurol. Disord. Drug Targets 8, 16-30. doi: 10.2174/ 187152709787601867

Demeester, N., Castro, G., Desrumaux, C., De Geitere, C., Fruchart, J. C., Santens, P., et al. (2000). Characterization and functional studies of lipoproteins, lipid transfer proteins, and lecithin:cholesterol acyltransferase in CSF of normal individuals and patients with Alzheimer's disease. J. Lipid Res. 41, 963-974.

Desai, P. P., Ikonomovic, M. D., Abrahamson, E. E., Hamilton, R. L., Isanski, B. A., Hope, C. E., et al. (2005). Apolipoprotein D is a component of compact but not diffuse amyloid-beta plaques in Alzheimer's disease temporal cortex. Neurobiol. Dis. 20, 574-582. doi: 10.1016/j.nbd.2005.04.012

dos Santos Rodrigues, B., Kanekiyo, T., and Singh, J. (2019). ApoE-2 braintargeted gene therapy through transferrin and penetratin tagged liposomal nanoparticles. Pharm. Res. 36:161. doi: 10.1007/s11095-019-2691-7

Drayna, D., Fielding, C., McLean, J., Baer, B., Castro, G., Chen, E., et al. (1986). Cloning and expression of human apolipoprotein D cDNA. J. Biol. Chem. 261, 16535-16539.

Eichinger, A., Nasreen, A., Kim, H. J., and Skerra, A. (2007). Structural insight into the dual ligand specificity and mode of high density lipoprotein association of apolipoprotein D. J. Biol. Chem. 282, 31068-31075. doi: 10.1074/jbc. M703552200

Elliott, D. A., Weickert, C. S., and Garner, B. (2010). Apolipoproteins in the brain: implications for neurological and psychiatric disorders. Clin. Lipidol. 51, 555-573. doi: 10.2217/CLP.10.37

Elshourbagy, N. A., Liao, W. S., Mahley, R. W., and Taylor, J. M. (1985). Apolipoprotein E mRNA is abundant in the brain and adrenals, as well as in 
the liver, and is present in other peripheral tissues of rats and marmosets. Proc. Natl. Acad. Sci. U S A. 82, 203-207. doi: 10.1073/pnas.82.1.203

Fagan, A. M., Holtzman, D. M., Munson, G., Mathur, T., Schneider, D., Chang, L. K., et al. (1999). Unique lipoproteins secreted by primary astrocytes from wild type, apoE (-/-), and human apoE transgenic mice. J. Biol. Chem. 274, 30001-30007. doi: 10.1074/jbc.274.42.30001

Fagan, A. M., Murphy, B. A., Patel, S. N., Kilbridge, J. F., Mobley, W. C., Bu, G., et al. (1998). Evidence for normal aging of the septo-hippocampal cholinergic system in apoE (-/-) mice but impaired clearance of axonal degeneration products following injury. Exp. Neurol. 151, 314-325. doi: 10.1006/exnr.1998.6818

Fernandez-de-Retana, S., Cano-Sarabia, M., Marazuela, P., Sanchez-Quesada, J. L., Garcia-Leon, A., Montanola, A., et al. (2017). Characterization of ApoJreconstituted high-density lipoprotein ( $\mathrm{rHDL}$ ) nanodisc for the potential treatment of cerebral beta-amyloidosis. Sci. Rep. 7:14637. doi: 10.1038/s41598017-15215-W

Fitz, N. F., Cronican, A. A., Saleem, M., Fauq, A. H., Chapman, R., Lefterov, I., et al. (2012). Abcal deficiency affects Alzheimer\&\#039;s disease-like phenotype in human ApoE4 but not in ApoE3-targeted replacement mice. J. Neurosci. 32:13125. doi: 10.1523/JNEUROSCI.1937-12.2012

Flower, D. R., North, A. C., and Sansom, C. E. (2000). The lipocalin protein family: structural and sequence overview. Biochim. Biophys. Acta 1482, 9-24. doi: 10.1016/s0167-4838(00)00148-5

Foley, E. M., Gordts, P., Stanford, K. I., Gonzales, J. C., Lawrence, R., Stoddard, N., et al. (2013). Hepatic remnant lipoprotein clearance by heparan sulfate proteoglycans and low-density lipoprotein receptors depend on dietary conditions in mice. Arterioscler. Thromb. Vasc. Biol. 33, 2065-2074. doi: 10. 1161/atvbaha.113.301637

Frias, J. C., Ma, Y., Williams, K. J., Fayad, Z. A., and Fisher, E. A. (2006). Properties of a versatile nanoparticle platform contrast agent to image and characterize atherosclerotic plaques by magnetic resonance imaging. Nano Lett. 6, 2220-2224. doi: 10.1021/nl061498r

Frias, J. C., Williams, K. J., Fisher, E. A., and Fayad, Z. A. (2004). Recombinant HDL-like nanoparticles: a specific contrast agent for MRI of atherosclerotic plaques. J. Am. Chem. Soc. 126, 16316-16317. doi: 10.1021/ja044911a

Fujiyoshi, M., Ohtsuki, S., Hori, S., Tachikawa, M., and Terasaki, T. (2007). 24Shydroxycholesterol induces cholesterol release from choroid plexus epithelial cells in an apical- and apoE isoform-dependent manner concomitantly with the induction of ABCA1 and ABCG1 expression. J. Neurochem. 100, 968-978. doi: 10.1111/j.1471-4159.2006.04240.x

Fung, K. Y., Wang, C., Nyegaard, S., Heit, B., Fairn, G. D., and Lee, W. L. (2017). SR-BI mediated transcytosis of HDL in brain microvascular endothelial cells is independent of Caveolin, Clathrin, and PDZK1. Front. Physiol. 8:841. doi: 10.3389/fphys.2017.00841

Ganfornina, M. D., Do Carmo, S., Lora, J. M., Torres-Schumann, S., Vogel, M., Allhorn, M., et al. (2008). Apolipoprotein D is involved in the mechanisms regulating protection from oxidative stress. Aging Cell. 7, 506-515. doi: 10.1111/ j.1474-9726.2008.00395.x

Gearing, M., Mirra, S. S., Hedreen, J. C., Sumi, S. M., Hansen, L. A., and Heyman, A. (1995). The consortium to establish a registry for Alzheimer's Disease (CERAD). Part X. Neuropathology confirmation of the clinical diagnosis of Alzheimer's disease. Neurology 45, 461-466. doi: 10.1212/wnl.45.3.461

Getz, G. S. (2005). Thematic review series: the immune system and atherogenesis. Bridging the innate and adaptive immune systems. J. Lipid Res. 46, 619-622. doi: 10.1194/jlr.E500002-JLR200

Gordon, S. M., Deng, J., Lu, L. J., and Davidson, W. S. (2010). Proteomic characterization of human plasma high density lipoprotein fractionated by gel filtration chromatography. J. Proteome Res. 9, 5239-5249. doi: 10.1021/ pr100520x

Gordts, P., and Esko, J. D. (2018). The heparan sulfate proteoglycan grip on hyperlipidemia and atherosclerosis. Matrix Biol. 71-72, 262-282. doi: 10.1016/j. matbio.2018.05.010

Gupta, A., and Iadecola, C. (2015). Impaired A $\beta$ clearance: a potential link between atherosclerosis and Alzheimer's disease. Front. Aging Neurosci. 7:115. doi: 10. 3389/fnagi.2015.00115

Hatters, D. M., Peters-Libeu, C. A., and Weisgraber, K. H. (2006). Apolipoprotein E structure: insights into function. Trends Biochem. Sci. 31, 445-454. doi: 10. 1016/j.tibs.2006.06.008
Herz, J., and Bock, H. H. (2002). Lipoprotein receptors in the nervous system. Annu. Rev. Biochem. 71, 405-434. doi: 10.1146/annurev.biochem.71.110601. 135342

Hirsch-Reinshagen, V., Maia, L. F., Burgess, B. L., Blain, J. F., Naus, K. E., McIsaac, S. A., et al. (2005). The absence of ABCA1 decreases soluble ApoE levels but does not diminish amyloid deposition in two murine models of Alzheimer disease. J. Biol. Chem. 280, 43243-43256. doi: 10.1074/jbc.M508781200

Holzer, M., Kern, S., Birner-Grunberger, R., Curcic, S., Heinemann, A., and Marsche, G. (2016). Refined purification strategy for reliable proteomic profiling of HDL2/3: Impact on proteomic complexity. Sci. Rep. 6:38533. doi: $10.1038 /$ srep38533

Hu, Y., Meuret, C., Martinez, A., Yassine, H., and Nedelkov, D. (2020). Distinct patterns of apolipoprotein C-I, C-II and C-III isoforms are associated with markers of Alzheimer's disease. J. Lipid Res. 62:100014. doi: 10.1194/jlr. RA120000919

Jeyarajah, E. J., Cromwell, W. C., and Otvos, J. D. (2006). Lipoprotein particle analysis by nuclear magnetic resonance spectroscopy. Clin. Lab. Med. 26, 847-870. doi: 10.1016/j.cll.2006.07.006

Johanson, C. E., Stopa, E. G., and McMillan, P. N. (2011). The blood-cerebrospinal fluid barrier: structure and functional significance. Methods Mol. Biol. 686, 101-131. doi: 10.1007/978-1-60761-938-3_4

Johnsen, K. B., Burkhart, A., Thomsen, L. B., Andresen, T. L., and Moos, T. (2019). Targeting the transferrin receptor for brain drug delivery. Prog. Neurobiol. 181:101665. doi: 10.1016/j.pneurobio.2019.101665

Johnsen, K. B., and Moos, T. (2016). Revisiting nanoparticle technology for bloodbrain barrier transport: Unfolding at the endothelial gate improves the fate of transferrin receptor-targeted liposomes. J. Control Release 222, 32-46. doi: 10.1016/j.jconrel.2015.11.032

Johnson, L. A., Olsen, R. H., Merkens, L. S., DeBarber, A., Steiner, R. D., Sullivan, P. M., et al. (2014). Apolipoprotein E-low density lipoprotein receptor interaction affects spatial memory retention and brain ApoE levels in an isoform-dependent manner. Neurobiol. Dis. 64, 150-162. doi: 10.1016/j.nbd. 2013.12.016

Kalman, J., McConathy, W., Araoz, C., Kasa, P., and Lacko, A. G. (2000). Apolipoprotein D in the aging brain and in Alzheimer's dementia. Neurol. Res. 22, 330-336. doi: 10.1080/01616412.2000.11740678

Kanekiyo, T., Xu, H., and Bu, G. (2014). ApoE and A $\beta$ in Alzheimer's disease: accidental encounters or partners? Neuron 81, 740-754. doi: 10.1016/j.neuron. 2014.01.045

Kang, D. E., Pietrzik, C. U., Baum, L., Chevallier, N., Merriam, D. E., Kounnas, M. Z., et al. (2000). Modulation of amyloid beta-protein clearance and Alzheimer's disease susceptibility by the LDL receptor-related protein pathway. J. Clin. Invest. 106, 1159-1166. doi: 10.1172/jci11013

Kawachi, E. (2015). Comparison of ${ }^{64} \mathrm{Cu}$ and ${ }^{68} \mathrm{Ga}$ for molecular imaging of atherosclerosis using the Apolipoprotein A-I Mimetic Peptide FAMP. J. Cardiovasc. Dis. Diagn. 3:3. doi: 10.4172/2329-9517.1000201

Kawachi, E., Uehara, Y., Hasegawa, K., Yahiro, E., Ando, S., Wada, Y., et al. (2013). Novel molecular imaging of atherosclerosis with gallium-68-labeled apolipoprotein A-I mimetic peptide and positron emission tomography. Circ. J. 77, 1482-1489. doi: 10.1253/circj.cj-12-0736

Kawano, M., Kawakami, M., Otsuka, M., Yashima, H., Yaginuma, T., and Ueki, A. (1995). Marked decrease of plasma apolipoprotein AI and AII in Japanese patients with late-onset non-familial Alzheimer's disease. Clin. Chim. Acta 239, 209-211. doi: 10.1016/0009-8981(95)06115-t

Kim, S. H., Kothari, S., Patel, A. B., Bielicki, J. K., and Narayanaswami, V. (2014). A pyrene based fluorescence approach to study conformation of apolipoprotein E3 in macrophage-generated nascent high density lipoprotein. Biochem. Biophys. Res. Commun. 450, 124-128. doi: 10.1016/j.bbrc.2014.05.071

Kim, W. S., Rahmanto, A. S., Kamili, A., Rye, K. A., Guillemin, G. J., Gelissen, I. C., et al. (2007). Role of ABCG1 and ABCA1 in regulation of neuronal cholesterol efflux to apolipoprotein $\mathrm{E}$ discs and suppression of amyloid-beta peptide generation. J. Biol. Chem. 282, 2851-2861. doi: 10.1074/jbc.M607831200 Pmid: 17121837.

Kim, W. S., Wong, J., Weickert, C. S., Webster, M. J., Bahn, S., and Garner, B. (2009). Apolipoprotein-D expression is increased during development and maturation of the human prefrontal cortex. J. Neurochem. 109, 1053-1066. doi: 10.1111/j.1471-4159.2009.06031.x 
Koch, M., Furtado, J. D., Falk, K., Leypoldt, F., Mukamal, K. J., and Jensen, M. K. (2017). Apolipoproteins and their subspecies in human cerebrospinal fluid and plasma. Alzheimers Dement. (Amst) 6, 182-187. doi: 10.1016/j.dadm.2017.01. 007

Koch, S., Donarski, N., Goetze, K., Kreckel, M., Stuerenburg, H. J., Buhmann, C., et al. (2001). Characterization of four lipoprotein classes in human cerebrospinal fluid. J. Lipid Res. 42, 1143-1151.

Koldamova, R., Staufenbiel, M., and Lefterov, I. (2005). Lack of ABCA1 considerably decreases brain ApoE level and increases amyloid deposition in APP23 mice. J. Biol. Chem. 280, 43224-43235. doi: 10.1074/jbc.M504513200

Kuklenyik, Z., Jones, J. I., Gardner, M. S., Schieltz, D. M., Parks, B. A., Toth, C. A., et al. (2018). Core lipid, surface lipid and apolipoprotein composition analysis of lipoprotein particles as a function of particle size in one workflow integrating asymmetric flow field-flow fractionation and liquid chromatography-tandem mass spectrometry. PLoS One 13:e0194797. doi: 10.1371/journal.pone.0194797

Kunitake, S. T., Jarvis, M. R., Hamilton, R. L., and Kane, J. P. (1992). Binding of transition metals by apolipoprotein A-I-containing plasma lipoproteins: inhibition of oxidation of low density lipoproteins. Proc. Natl. Acad. Sci. U S A. 89, 6993-6997. doi: 10.1073/pnas.89.15.6993

Ladu, M. J., Reardon, C., Van Eldik, L., Fagan, A. M., Bu, G., Holtzman, D., et al. (2000). Lipoproteins in the central nervous system. Ann. N Y. Acad. Sci. 903, 167-175. doi: 10.1111/j.1749-6632.2000.tb06365.x

Lagerstedt, J. O., Petrlova, J., Hilt, S., Marek, A., Chung, Y., Sriram, R., et al. (2013). EPR assessment of protein sites for incorporation of Gd(III) MRI contrast labels. Contrast Media Mol. Imaging 8, 252-264. doi: 10.1002/cmmi.1518

Lefterov, I., Fitz, N. F., Cronican, A. A., Fogg, A., Lefterov, P., Kodali, R., et al. (2010). Apolipoprotein A-I deficiency increases cerebral amyloid angiopathy and cognitive deficits in APP/PS1DeltaE9 mice. J. Biol. Chem. 285, 3694536957. doi: 10.1074/jbc.M110.127738

Lemere, C. A., Spooner, E. T., LaFrancois, J., Malester, B., Mori, C., Leverone, J. F., et al. (2003). Evidence for peripheral clearance of cerebral Abeta protein following chronic, active Abeta immunization in PSAPP mice. Neurobiol. Dis. 14, 10-18. doi: 10.1016/s0969-9961(03)00044-5

Lewis, T. L., Cao, D., Lu, H., Mans, R. A., Su, Y. R., Jungbauer, L., et al. (2010). Overexpression of human apolipoprotein A-I preserves cognitive function and attenuates neuroinflammation and cerebral amyloid angiopathy in a mouse model of Alzheimer disease. J. Biol. Chem. 285, 36958-36968. doi: 10.1074/jbc. M110.127829

Liao, F., Li, A., Xiong, M., Bien-Ly, N., Jiang, H., Zhang, Y., et al. (2018). Targeting of nonlipidated, aggregated apoE with antibodies inhibits amyloid accumulation. J. Clin. Invest. 128, 2144-2155. doi: 10.1172/JCI96429

Lillis, A. P., Van Duyn, L. B., Murphy-Ullrich, J. E., and Strickland, D. K. (2008). LDL receptor-related protein 1: unique tissue-specific functions revealed by selective gene knockout studies. Physiol. Rev. 88, 887-918. doi: 10.1152/physrev. 00033.2007

Linton, M. F., Gish, R., Hubl, S. T., Butler, E., Esquivel, C., Bry, W. I., et al. (1991). Phenotypes of apolipoprotein B and apolipoprotein E after liver transplantation. J. Clin. Invest. 88, 270-281. doi: 10.1172/jci115288

Liu, M., Kuhel, D. G., Shen, L., Hui, D. Y., and Woods, S. C. (2012). Apolipoprotein E does not cross the blood-cerebrospinal fluid barrier, as revealed by an improved technique for sampling CSF from mice. Am. J. Physiol. Regul. Integr. Comp. Physiol. 303, R903-R908. doi: 10.1152/ajpregu.00219.2012

Mahley, R. W. (1988). Apolipoprotein E: cholesterol transport protein with expanding role in cell biology. Science 240, 622-630. doi: 10.1126/science. 3283935

Mahley, R. W. (2016). Central nervous system lipoproteins: ApoE and regulation of cholesterol metabolism. Arterioscler. Thromb. Vasc. Biol. 36, 1305-1315. doi: 10.1161/atvbaha.116.307023

Mahley, R. W., and Huang, Y. (2012). Apolipoprotein e sets the stage: response to injury triggers neuropathology. Neuron 76, 871-885. doi: 10.1016/j.neuron. 2012.11 .020

Mangaraj, M., Nanda, R., and Panda, S. (2016). Apolipoprotein A-I: A molecule of diverse function. Indian J. Clin. Biochem. 31, 253-259. doi: 10.1007/s12291015-0513-1

Martin-Nizard, F., Meresse, S., Cecchelli, R., Fruchart, J. C., and Delbart, C. (1989). Interactions of high-density lipoprotein 3 with brain capillary endothelial cells. Biochim. Biophys. Acta 1005, 201-208. doi: 10.1016/0005-2760(89)90038-6
McPherson, P. A., Young, I. S., and McEneny, J. (2007b). A dual role for lecithin:cholesterol acyltransferase (EC 2.3.1.43) in lipoprotein oxidation. Free Radic. Biol. Med. 43, 1484-1493. doi: 10.1016/j.freeradbiomed.2007.08.007

McPherson, P. A., Young, I. S., McKibben, B., and McEneny, J. (2007a). High density lipoprotein subfractions: isolation, composition, and their duplicitous role in oxidation. J. Lipid Res. 48, 86-95. doi: 10.1194/jlr.M600094-JLR200

Meaney, S., Hassan, M., Sakinis, A., Lutjohann, D., von Bergmann, K., Wennmalm, A., et al. (2001). Evidence that the major oxysterols in human circulation originate from distinct pools of cholesterol: a stable isotope study. J. Lipid Res. 42, 70-78.

Mehta, D., and Malik, A. B. (2006). Signaling mechanisms regulating endothelial permeability. Physiol. Rev. 86, 279-367. doi: 10.1152/physrev.00012.2005

Memisogullari, R., and Bakan, E. (2004). Levels of ceruloplasmin, transferrin, and lipid peroxidation in the serum of patients with Type 2 diabetes mellitus. J. Diabetes Complications 18, 193-197. doi: 10.1016/S1056-8727(03)00032-1

Merched, A., Xia, Y., Visvikis, S., Serot, J. M., and Siest, G. (2000). Decreased highdensity lipoprotein cholesterol and serum apolipoprotein AI concentrations are highly correlated with the severity of Alzheimer's disease. Neurobiol. Aging 21, 27-30.

Merino-Zamorano, C., Fernandez-de Retana, S., Montanola, A., Batlle, A., SaintPol, J., Mysiorek, C., et al. (2016). Modulation of Amyloid-beta1-40 Transport by ApoA1 and ApoJ Across an in vitro model of the blood-brain barrier. J. Alzheimers Dis. 53, 677-691. doi: 10.3233/JAD-150976

Mizuno, S., Mihara, T., Miyaoka, T., Inagaki, T., and Horiguchi, J. (2005). CSF iron, ferritin and transferrin levels in restless legs syndrome. J. Sleep Res. 14, 43-47. doi: 10.1111/j.1365-2869.2004.00403.x

Montine, K. S., Bassett, C. N., Ou, J. J., Markesbery, W. R., Swift, L. L., and Montine, T. J. (1998). Apolipoprotein E allelic influence on human cerebrospinal fluid apolipoproteins. J. Lipid Res. 39, 2443-2451.

Nichols, A. V., Krauss, R. M., and Musliner, T. A. (1986). Nondenaturing polyacrylamide gradient gel electrophoresis. Methods Enzymol. 128, 417-431. doi: 10.1016/0076-6879(86)28084-2

Olivieri, O., Martinelli, N., Bassi, A., Trabetti, E., Girelli, D., Pizzolo, F., et al. (2007). ApoE epsilon2/epsilon3/epsilon4 polymorphism, ApoC-III/ApoE ratio and metabolic syndrome. Clin. Exp. Med. 7, 164-172. doi: 10.1007/s10238-0070142-y

Otvos, J. D., Jeyarajah, E. J., Bennett, D. W., and Krauss, R. M. (1992). Development of a proton nuclear magnetic resonance spectroscopic method for determining plasma lipoprotein concentrations and subspecies distributions from a single, rapid measurement. Clin. Chem. 38, 1632-1638.

Paula-Lima, A. C., Tricerri, M. A., Brito-Moreira, J., Bomfim, T. R., Oliveira, F. F., Magdesian, M. H., et al. (2009). Human apolipoprotein A-I binds amyloidbeta and prevents Abeta-induced neurotoxicity. Int. J. Biochem. Cell. Biol. 41, 1361-1370. doi: 10.1016/j.biocel.2008.12.003

Pearson, K., Saito, H., Woods, S. C., Lund-Katz, S., Tso, P., Phillips, M. C., et al. (2004). Structure of human apolipoprotein A-IV: a distinct domain architecture among exchangeable apolipoproteins with potential functional implications. Biochemistry 43, 10719-10729. doi: 10.1021/bi048978m

Pérez-Medina, C., Binderup, T., Lobatto, M. E., Tang, J., Calcagno, C., Giesen, L., et al. (2016). In Vivo PET imaging of HDL in multiple atherosclerosis models. JACC Cardiovasc. Imaging 9, 950-961. doi: 10.1016/j.jcmg.2016.01.020

Provost, P. R., Weech, P. K., Tremblay, N. M., Marcel, Y. L., and Rassart, E. (1990). Molecular characterization and differential mRNA tissue distribution of rabbit apolipoprotein D. J. Lipid Res. 31, 2057-2065.

Ramos-Cabrer, P., Fay, F., Sanchez-Gaytan, B. L., Tang, J., Castillo, J., Fayad, Z. A., et al. (2016). Conformational changes in high-density lipoprotein nanoparticles induced by high payloads of paramagnetic lipids. ACS Omega. 1, 470-475. doi: 10.1021/acsomega.6b00108

Rassart, E., Bedirian, A., Do Carmo, S., Guinard, O., Sirois, J., Terrisse, L., et al. (2000). Apolipoprotein D. Biochim. Biophys. Acta 1482, 185-198. doi: 10.1016/ s0167-4838(00)00162-x

Rawat, V., Wang, S., Sima, J., Bar, R., Liraz, O., Gundimeda, U., et al. (2019). ApoE4 Alters ABCA1 membrane trafficking in astrocytes. J. Neurosci. 39, 9611-9622. doi: 10.1523/JNEUROSCI.1400-19.2019

Reed, B., Villeneuve, S., Mack, W., DeCarli, C., Chui, H. C., and Jagust, W. (2014). Associations between serum cholesterol levels and cerebral amyloidosis. JAMA Neurol. 71, 195-200. doi: 10.1001/jamaneurol.2013.5390 
Remaley, A. T., Stonik, J. A., Demosky, S. J., Neufeld, E. B., Bocharov, A. V., Vishnyakova, T. G., et al. (2001). Apolipoprotein specificity for lipid efflux by the human ABCAI transporter. Biochem. Biophys. Res. Commun. 280, 818-823. doi: 10.1006/bbrc.2000.4219

Robert, J., Button, E. B., Martin, E. M., McAlary, L., Gidden, Z., Gilmour, M., et al. (2020). Cerebrovascular amyloid Angiopathy in bioengineered vessels is reduced by high-density lipoprotein particles enriched in Apolipoprotein E. Mol. Neurodegen. 15:23. doi: 10.1186/s13024-020-00366-8

Robert, J., Button, E. B., Yuen, B., Gilmour, M., Kang, K., Bahrabadi, A., et al. (2017). Clearance of beta-amyloid is facilitated by apolipoprotein E and circulating high-density lipoproteins in bioengineered human vessels. Elife 6:e29595. doi: 10.7554/eLife.29595

Rohrer, L., Ohnsorg, P. M., Lehner, M., Landolt, F., Rinninger, F., and von Eckardstein, A. (2009). High-density lipoprotein transport through aortic endothelial cells involves scavenger receptor BI and ATP-binding cassette transporter G1. Circ Res. 104, 1142-1150. doi: 10.1161/circresaha.108.19 0587

Rui, M., Guo, W., Ding, Q., Wei, X., Xu, J., and Xu, Y. (2012). Recombinant highdensity lipoprotein nanoparticles containing gadolinium-labeled cholesterol for morphologic and functional magnetic resonance imaging of the liver. Int. J. Nanomed. 7, 3751-3768. doi: 10.2147/ijn.S33139

Ruzali, W. A., Kehoe, P. G., and Love, S. (2012). LRP1 expression in cerebral cortex, choroid plexus and meningeal blood vessels: relationship to cerebral amyloid angiopathy and APOE status. Neurosci. Lett. 525, 123-128. doi: 10. 1016/j.neulet.2012.07.065

Shen, Z. T., Zheng, S., Gounis, M. J., and Sigalov, A. B. (2015). Diagnostic magnetic resonance imaging of atherosclerosis in Apolipoprotein E knockout mouse model using macrophage-targeted gadolinium-containing synthetic lipopeptide nanoparticles. PLoS One 10:e143453. doi: 10.1371/journal.pone. 0143453

Shibata, M., Yamada, S., Kumar, S. R., Calero, M., Bading, J., Frangione, B., et al. (2000). Clearance of Alzheimer's amyloid-ss(1-40) peptide from brain by LDL receptor-related protein-1 at the blood-brain barrier. J. Clin. Invest. 106, 1489-1499. doi: 10.1172/jci10498

Shih, Y. H., Tsai, K. J., Lee, C. W., Shiesh, S. C., Chen, W. T., Pai, M. C., et al. (2014). Apolipoprotein C-III is an amyloid- $\beta$-binding protein and an early marker for Alzheimer's disease. J. Alzheimers Dis. 41, 855-865. doi: 10.3233/jad-140111

Sigalov, A. B. (2014). Nature-inspired nanoformulations for contrast-enhanced in vivo MR imaging of macrophages. Contrast Media Mol. Imaging 9, 372-382. doi: $10.1002 / \mathrm{cmmi} .1587$

Song, H., Ma, X., Xu, J., Song, Q., Hu, M., Gu, X., et al. (2018). The shape effect of reconstituted high-density lipoprotein nanocarriers on brain delivery and $A \beta$ clearance. Nano Res. 11, 5615-5628. doi: 10.1007/s12274-018-2107-8

Song, Q., Huang, M., Yao, L., Wang, X., Gu, X., Chen, J., et al. (2014). Lipoproteinbased nanoparticles rescue the memory loss of mice with Alzheimer's disease by accelerating the clearance of amyloid-beta. ACS Nano. 8, 2345-2359. doi: $10.1021 / \mathrm{nn} 4058215$

Song, Q., Song, H., Xu, J., Huang, J., Hu, M., Gu, X., et al. (2016). Biomimetic ApoEReconstituted high density lipoprotein nanocarrier for blood-brain barrier penetration and amyloid beta-targeting drug Delivery. Mol. Pharm. 13, 39763987. doi: 10.1021/acs.molpharmaceut.6b00781

Sriram, R., Lagerstedt, J. O., Petrlova, J., Samardzic, H., Kreutzer, U., Xie, H., et al. (2011). Imaging apolipoprotein AI in vivo. NMR Biomed. 24, 916-924. doi: $10.1002 / \mathrm{nbm} .1650$

Storck, S. E., Meister, S., Nahrath, J., Meißner, J. N., Schubert, N., Di Spiezio, A., et al. (2016). Endothelial LRP1 transports amyloid- $\beta(1-42)$ across the bloodbrain barrier. J. Clin. Invest. 126, 123-136. doi: 10.1172/jci81108

Strazielle, N., and Ghersi-Egea, J. F. (2016). Potential pathways for CNS drug delivery across the blood-cerebrospinal fluid barrier. Curr. Pharm. Des. 22, 5463-5476. doi: 10.2174/1381612822666160726112115

Stukas, S., Robert, J., Lee, M., Kulic, I., Carr, M., Tourigny, K., et al. (2014a). Intravenously injected human apolipoprotein A-I rapidly enters the central nervous system via the choroid plexus. J. Am. Heart Assoc. 3:e001156. doi: 10.1161/JAHA.114.001156

Stukas, S., Robert, J., and Wellington, C. L. (2014b). High-density lipoproteins and cerebrovascular integrity in Alzheimer's disease. Cell. Metab. 19, 574-591. doi: 10.1016/j.cmet.2014.01.003
Suzuki, T., Tozuka, M., Kazuyoshi, Y., Sugano, M., Nakabayashi, T., Okumura, N., et al. (2002). Predominant apolipoprotein J exists as lipid-poor mixtures in cerebrospinal fluid. Ann. Clin. Lab. Sci. 32, 369-376.

Swaminathan, S. K., Zhou, A. L., Ahlschwede, K. M., Curran, G. L., Lowe, V. J., Li, L., et al. (2020). High-density lipoprotein mimetic peptide $4 \mathrm{~F}$ efficiently crosses the blood-brain barrier and modulates amyloid-beta distribution between brain and plasma. J Pharmacol. Exp. Ther. 375, 308-316. doi: 10.1124/jpet.120.265876

Terrisse, L., Poirier, J., Bertrand, P., Merched, A., Visvikis, S., Siest, G., et al. (1998). Increased levels of apolipoprotein $\mathrm{D}$ in cerebrospinal fluid and hippocampus of Alzheimer's patients. J. Neurochem. 71, 1643-1650. doi: 10.1046/j.1471-4159. 1998.71041643.x

Timmins, J., Lee, J., Boudyguina, E., Kluckman, K., Brunham, L., Mulya, A., et al. (2005). Targeted inactivation of hepatic Abcal causes profound hypoalphalipoproteinemia and kidney hypercatabolism of apoA-I. J. Clin. Invest. 115, 1333-1342.

Ullman, J. C., Arguello, A., Getz, J. A., Bhalla, A., Mahon, C. S., Wang, J., et al. (2020). Brain delivery and activity of a lysosomal enzyme using a blood-brain barrier transport vehicle in mice. Sci. Transl. Med. 12:eaay1163. doi: 10.1126/ scitranslmed.aay1163

Vaisar, T., Pennathur, S., Green, P. S., Gharib, S. A., Hoofnagle, A. N., Cheung, M. C., et al. (2007). Shotgun proteomics implicates protease inhibition and complement activation in the antiinflammatory properties of HDL. J. Clin. Invest. 117, 746-756. doi: 10.1172/JCI26206

Verghese, P. B., Castellano, J. M., Garai, K., Wang, Y., Jiang, H., Shah, A., et al. (2013). ApoE influences amyloid- $\beta$ (A $\beta$ ) clearance despite minimal apoE/A $\beta$ association in physiological conditions. Proc. Natl. Acad. Sci. U S A. 110, E1807-E1816. doi: 10.1073/pnas.1220484110

Visser, C. C., Voorwinden, L. H., Crommelin, D. J., Danhof, M., and de Boer, A. G. (2004). Characterization and modulation of the transferrin receptor on brain capillary endothelial cells. Pharm. Res. 21, 761-769. doi: 10.1023/b:pham. $0000026425.69874 .8 \mathrm{e}$

Vitali, C., Wellington, C. L., and Calabresi, L. (2014). HDL and cholesterol handling in the brain. Cardiovasc. Res. 103, 405-413.

von Zychlinski, A., Williams, M., McCormick, S., and Kleffmann, T. (2014). Absolute quantification of apolipoproteins and associated proteins on human plasma lipoproteins. J. Proteom. 106, 181-190. doi: 10.1016/j.jprot.2014.04.030

Wahrle, S. E., Jiang, H., Parsadanian, M., Hartman, R. E., Bales, K. R., Paul, S. M., et al. (2005). Deletion of Abcal increases Abeta deposition in the PDAPP transgenic mouse model of Alzheimer disease. J. Biol. Chem. 280, 43236-43242. doi: 10.1074/jbc.M508780200

Wahrle, S. E., Jiang, H., Parsadanian, M., Kim, J., Li, A., Knoten, A., et al. (2008). Overexpression of ABCA1 reduces amyloid deposition in the PDAPP mouse model of Alzheimer disease. J. Clin. Invest. 118, 671-682. doi: 10.1172/JCI33622

Wahrle, S. E., Jiang, H., Parsadanian, M., Legleiter, J., Han, X., Fryer, J. D., et al. (2004). ABCA1 is required for normal central nervous system ApoE levels and for lipidation of astrocyte-secreted apoE. J. Biol. Chem. 279, 40987-40993. doi: 10.1074/jbc.M407963200

Wang, H., and Eckel, R. H. (2014). What are lipoproteins doing in the brain? Trends Endocrinol. Metab. 25, 8-14. doi: 10.1016/j.tem.2013.10.003

Wang, Q., Chen, S., Luo, Q., Liu, M., and Zhou, X. (2015). A europium-lipoprotein nanocomposite for highly-sensitive MR-fluorescence multimodal imaging. RSC Adv. 5, 1808-1811. doi: 10.1039/C4RA12201A

Wang, Q., Zhou, W., and Zhang, J. (2019). Higher apolipoprotein C-III levels in cerebrospinal fluid are associated with slower cognitive decline in mild cognitive impairment. J. Alzheimers Dis. 67, 961-969. doi: 10.3233/jad-181096

Wiley, D. T., Webster, P., Gale, A., and Davis, M. E. (2013). Transcytosis and brain uptake of transferrin-containing nanoparticles by tuning avidity to transferrin receptor. Proc. Natl. Acad. Sci. U S A. 110, 8662-8667. doi: 10.1073/pnas. 1307152110

Yamauchi, K., Tozuka, M., Hidaka, H., Hidaka, E., Kondo, Y., and Katsuyama, T. (1999). Characterization of apolipoprotein E-containing lipoproteins in cerebrospinal fluid: effect of phenotype on the distribution of apolipoprotein E. Clin. Chem. 45, 1431-1438.

Yassine, H. N., Feng, Q., Chiang, J., Petrosspour, L. M., Fonteh, A. N., Chui, H. C., et al. (2016). ABCA1-mediated cholesterol efflux capacity to cerebrospinal fluid is reduced in patients with mild cognitive impairment and Alzheimer's Disease. J. Am. Heart Assoc. 5:e002886. doi: 10.1161/JAHA.115.002886 
Yong-Sang, J., Dioury, F., Meneyrol, V., Ait-Arsa, I., Idoumbin, J. P., Guibbal, F., et al. (2019). Development, synthesis, and (68)Ga-Labeling of a Lipophilic complexing agent for atherosclerosis PET imaging. Eur. J. Med. Chem. 176, 129-134. doi: 10.1016/j.ejmech.2019.05.002

Zhang, Z., Cao, W., Jin, H., Lovell, J. F., Yang, M., Ding, L., et al. (2009). Biomimetic nanocarrier for direct cytosolic drug delivery. Angew Chem. Int. Ed. Engl. 48, 9171-9175. doi: 10.1002/anie.200903112

Zheng, K. H., van der Valk, F. M., Smits, L. P., Sandberg, M., Dasseux, J. L., Baron, R., et al. (2016). HDL mimetic CER-001 targets atherosclerotic plaques in patients. Atherosclerosis 251, 381-388. doi: 10.1016/j.atherosclerosis.2016.05. 038

Zhou, A. L., Swaminathan, S. K., Curran, G. L., Poduslo, J. F., Lowe, V. J., Li, L., et al. (2019). Apolipoprotein A-I crosses the blood-brain barrier through clathrinindependent and cholesterol-mediated endocytosis. J. Pharmacol. Exp. Ther. 369, 481-488. doi: 10.1124/jpet.118.254201

Zhou, Y., Zhu, F., Liu, Y., Zheng, M., Wang, Y., Zhang, D., et al. (2020). Blood-brain barrier-penetrating siRNA nanomedicine for Alzheimer's disease therapy. Sci. Adv. 6:eabc7031. doi: 10.1126/sciadv.abc7031

Zlokovic, B. V., Martel, C. L., Matsubara, E., McComb, J. G., Zheng, G., McCluskey, R. T., et al. (1996). Glycoprotein 330/megalin: probable role in receptormediated transport of apolipoprotein J alone and in a complex with Alzheimer disease amyloid beta at the blood-brain and blood-cerebrospinal fluid barriers. Proc. Natl. Acad. Sci. U S A. 93, 4229-4234. doi: 10.1073/pnas.93.9.4229
Zuin, M., Cervellati, C., Trentini, A., Passaro, A., Rosta, V., Zimetti, F., et al. (2021). Association between Serum concentrations of apolipoprotein A-I (ApoA-I) and Alzheimer's Disease: systematic review and meta-analysis. Diagnostics 11:984 doi: 10.3390/diagnostics110 60984

Conflict of Interest: The authors declare that the research was conducted in the absence of any commercial or financial relationships that could be construed as a potential conflict of interest.

Publisher's Note: All claims expressed in this article are solely those of the authors and do not necessarily represent those of their affiliated organizations, or those of the publisher, the editors and the reviewers. Any product that may be evaluated in this article, or claim that may be made by its manufacturer, is not guaranteed or endorsed by the publisher.

Copyright (c) 2021 Van Valkenburgh, Meuret, Martinez, Kodancha, Solomon, Chen and Yassine. This is an open-access article distributed under the terms of the Creative Commons Attribution License (CC BY). The use, distribution or reproduction in other forums is permitted, provided the original author(s) and the copyright owner(s) are credited and that the original publication in this journal is cited, in accordance with accepted academic practice. No use, distribution or reproduction is permitted which does not comply with these terms. 